Catalysis

Manuscript Number:

Title: Bimetallic Ni-Co/SBA-15 Catalysts for Reforming of Ethanol: How Cobalt Modifies the Nickel Metal Phase and Product Distribution

\author{
Article Type: Research Paper \\ Section/Category: Heterogeneous catalysis
}

Keywords: nickel cobalt catalysts; in situ XPS; hydrogen production; cobalt carbide; ethanol steam reforming

Corresponding Author: Professor Alfonso Caballero,

Corresponding Author's Institution: University of Seville

First Author: Alfonso Caballero

Order of Authors: Alfonso Caballero; Alberto Rodriguez-Gomez

Abstract: In this study, five mono and bimetallic xNi-(10-x) Co/SBA-15 catalysts $(x=10,8,5,2$ and 0 , with a total metallic content of 10 wto) have been synthesized using a deposition-precipitation (DP) methodology. Catalytic performances on the steam reforming of ethanol reaction (SRE) have been determined and correlated with their physical and chemical state. A nickel content of 5\% or higher yields catalytic systems with good activity, high selectivity to hydrogen and a low production of acetaldehyde (less than 5\%). However, in the systems where the cobalt is the main component of the metallic phase (8-10\%), the selectivity changes, mainly due to the production of an excess of acetaldehyde, which is also reflected in the larger $\mathrm{H} 2 / \mathrm{CO} 2$ ratio. In agreement with previous findings, this important modification in the selectivity comes from the formation of a cobalt carbide phase, where only takes place in the cobalt enriched systems, and is inhibited with nickel content larger than 5\%. The formation of this carbide phase seems to be responsible for the decrease of cobalt particle size during the SRE reaction. Even though this cobalt carbide phase is thermodynamically metastable against decomposition to metallic cobalt and graphite carbon, our results have shown that it only reacts and decomposes after a hydrogen treatment at 600 oC. 


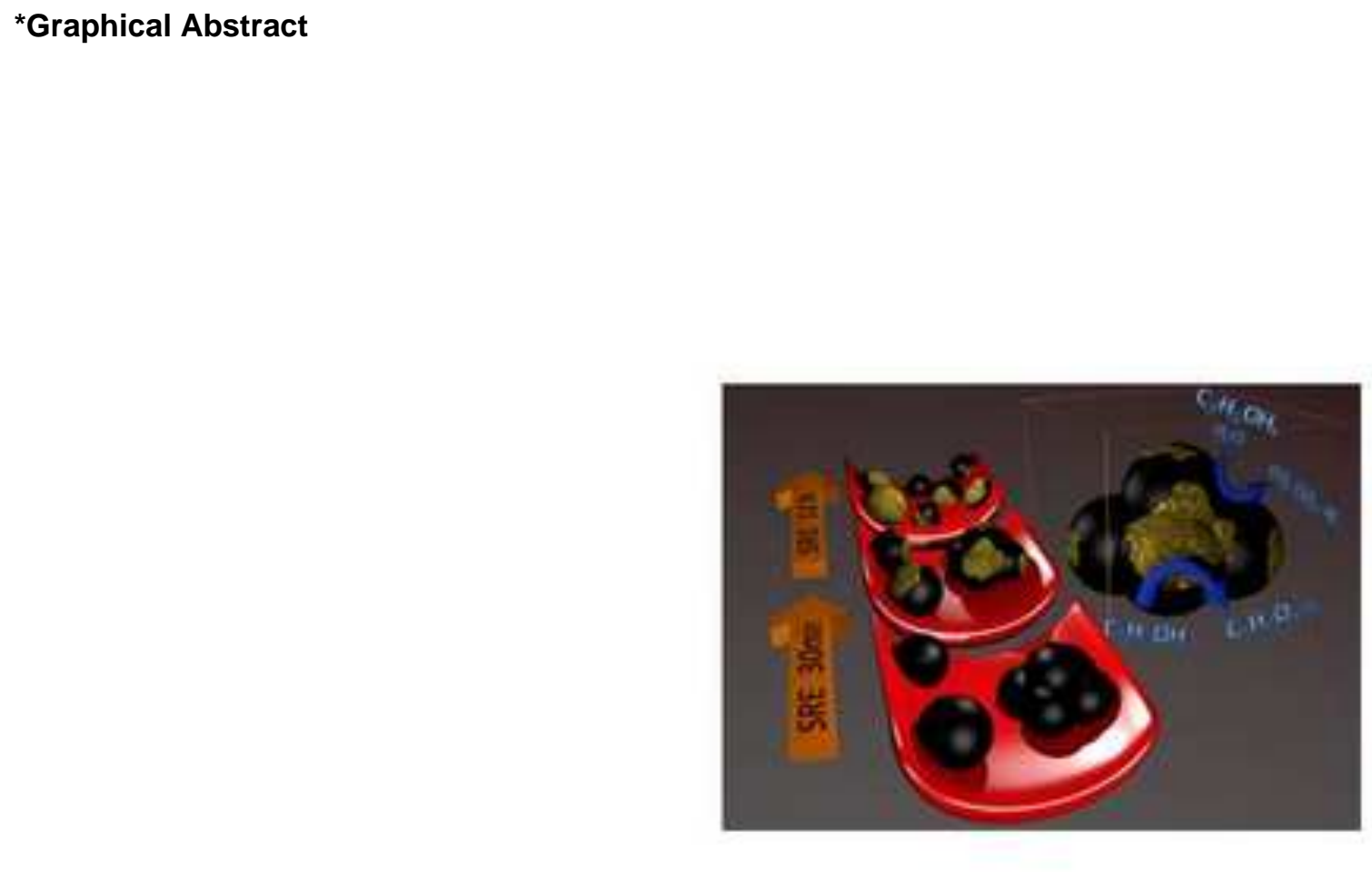

${ }^{*}$ Graphical Abstract
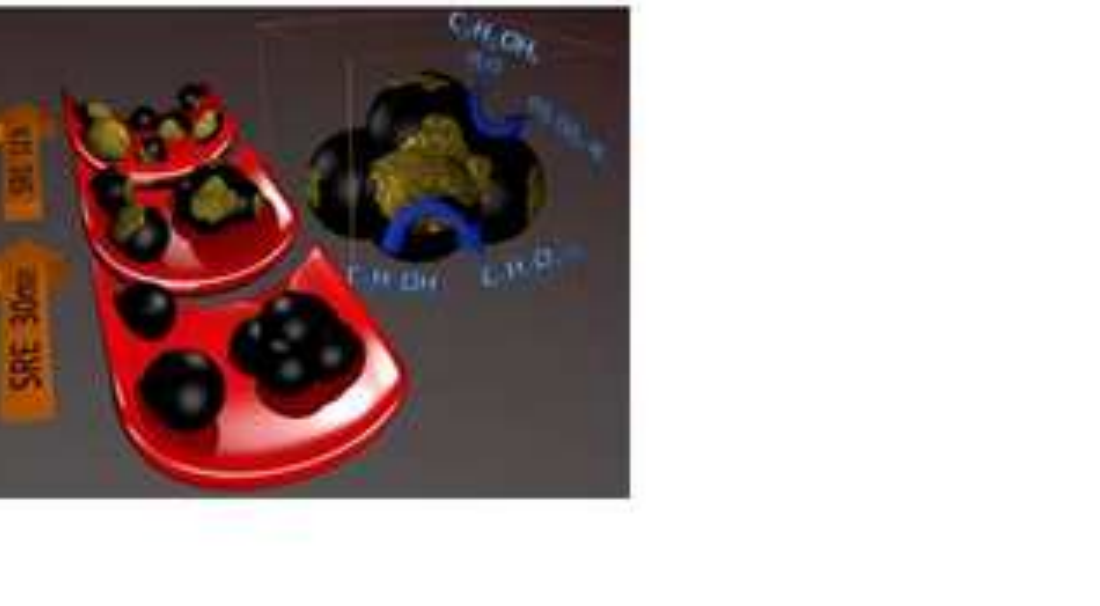


\section{Highlights}

- Five Ni and/or Cobalt catalysts supported on SBA-15 has been prepared by reduction of highly dispersed nickel/cobalt silicate phases

- Both metals form a bimetallic phase and the presence of nickel improves the dispersion of cobalt metallic phase

- When Co is the main metallic component, a carbide phase is formed during the ethanol reforming reaction

- This carbide phase increases the acetaldehyde production and redisperses the cobalt particles 


\title{
Bimetallic Ni-Co/SBA-15 Catalysts for Reforming of Ethanol: How Cobalt Modifies the Nickel Metal Phase and Product Distribution
}

\author{
Alberto Rodriguez-Gomez and Alfonso Caballero* \\ Instituto de Ciencia de Materiales de Sevilla (CSIC-University of Seville) and \\ Departamento de Quimica Inorganica, University of Seville. Av. Americo Vespucio, 49. \\ 41092. Seville, Spain. \\ caballero@us.es
}

\section{Abstract}

In this study, five mono and bimetallic $x \mathrm{Ni}-(10-\mathrm{x}) \mathrm{Co} / \mathrm{SBA}-15$ catalysts $(x=10,8,5$, 2 and 0 , with a total metallic content of $10 \mathrm{wt} \%$ ) have been synthesized using a deposition-precipitation (DP) methodology. Catalytic performances on the steam reforming of ethanol reaction (SRE) have been determined and correlated with their physical and chemical state. A nickel content of $5 \%$ or higher yields catalytic systems with good activity, high selectivity to hydrogen and a low production of acetaldehyde (less than 5\%). However, in the systems where the cobalt is the main component of the metallic phase (8-10\%), the selectivity changes, mainly due to the production of an excess of acetaldehyde, which is also reflected in the larger $\mathrm{H}_{2} / \mathrm{CO}_{2}$ ratio. In agreement with previous findings, this important modification in the selectivity comes from the formation of a cobalt carbide phase, where only takes place in the cobalt enriched systems, and is inhibited with nickel content larger than 5\%. The formation of this carbide phase seems to be responsible for the decrease of cobalt particle size during the SRE reaction. Even though this cobalt carbide phase is thermodynamically metastable against decomposition to metallic cobalt and graphite carbon, our results have shown that it only reacts and decomposes after a hydrogen treatment at $600{ }^{\circ} \mathrm{C}$.

Keywords: nickel cobalt catalysts, in situ XPS, hydrogen production, cobalt carbide, ethanol steam reforming, acetaldehyde.

\section{Introduction}

Although methane steam reforming is currently the most industrial competitive process for obtaining hydrogen [1-3], the impact on climate of using fossil fuels, and the limited availability of methane due to the remote locations of some of the major 
natural gas fields makes the use of renewable chemicals as bioethanol a very interesting alternative to reduce the environmental impact $[4,5]$. This product of the biomass processing is easily available, with low toxicity and also very important, the existing infrastructure for storage and transportation is spread worldwide [6-8]. Ethanol steam reforming has been extensively studied in the last decades. As in other reactions such as the methane reforming, the use of noble metals yields good catalytic performance with high selectivity to hydrogen and a limited amount of carbon deposits poisoning the catalyst [9-14]. Once again, the high price and poor availability of metals as $\mathrm{Ru}, \mathrm{Pt}, \mathrm{Rh}$ or $\mathrm{Pd}$, advises the use of cheaper alternatives, especially $\mathrm{Ni}$, but also Co and/or $\mathrm{Cu}$ [15-19], even though these metals favor the deposition of carbonaceous deposits. The carbon deposition processes can be mitigated in several ways, as changing the ethanol/water ratio, introducing oxygen in the feed mixture or using different kind of supports [20,21]. An alternative strategy to overcome this issue involves the use of bimetallic systems, where the synergistic effects of the two metals can improve their catalytic performances. In this sense $\mathrm{Ni}-\mathrm{Co}$ is one of the most popular couple being used for this SRE reaction but also for reforming of methane $[19,22-26]$. It has been previously reported that the combining effect of this two metals is able to produce less amount but also less harmful carbon deposits [6].

In this work we have synthesized five catalysts containing nickel and/or cobalt supported on the mesoporous silica SBA-15. The catalytic systems, with a total metal loading of $10 \mathrm{wt} \%$, has been prepared by means of a deposition-precipitation method ( $x$ Ni-(10-x)Co/SBA-15 catalysts, $x=10,8,5,2$ and 0$)$. We have measured the catalytic performances of these systems, and characterized their states after calcination, hydrogen reduction and steam reforming of ethanol reaction conditions using among others, XPS, XAS and TEM. The results have allowed correlating the catalytic performances with the initial state of metallic phases and its evolution under catalytic conditions. The formation of a Ni-Co bimetallic phase and the stabilization of a cobalt carbide phase in the Co-enriched systems are the major factors determining the catalytic performances of these $\mathrm{Ni}-\mathrm{Co} / \mathrm{SBA}-15$ catalysts.

\section{Experimental}




\subsection{Preparation of the catalysts}

$\mathrm{Ni}$-Co catalytic systems were synthesized by a deposition-precipitation method over a mesoporous support of SBA-15 which was prepared by the Zhao et al. protocol [27] using a TEOS/P123/HCl/ $\mathrm{H}_{2} \mathrm{O}$ (TEOS: Sigma-Aldrich, CAS: 78-10-4; $\mathrm{HCl}$ : SigmaAldrich, CAS: 7647-01-0; Pluronic ${ }^{\circledR}$ P-123: Sigma-Aldrich, CAS: 9003-11-6) molar relation of 1/0.02/9.91/320. Typically, $3 \mathrm{~g}$ of PEG-PPG-PEG (P123) were dissolved in $140 \mathrm{~mL}$ of $\mathrm{HCl} 1.8 \mathrm{M}$. After total solution, the mix was heated up to $50{ }^{\circ} \mathrm{C}$ and $5.9 \mathrm{~mL}$ of TEOS were added with stirring. The solution was kept on static at $50{ }^{\circ} \mathrm{C}$ for 18 hours, and the gel obtained was filtered and washed several times with distilled water. The product was dried and calcined on static air for 3 hours at $550{ }^{\circ} \mathrm{C}$. The metallic phase was loaded by heating up to $105{ }^{\circ} \mathrm{C}$ during 2 hours a solution containing $1 \mathrm{~g}$ of asprepared SBA-15, $150 \mathrm{~mL}$ of $\mathrm{HNO}_{3} 0.01 \mathrm{M}$ (Sigma-Aldrich, CAS: 7697-37-2), the metal precursors $\left[\mathrm{Ni}\left(\mathrm{NO}_{3}\right)_{2} \cdot 6 \mathrm{H}_{2} \mathrm{O}\right.$ (Panreac, CAS: $\left.13478-00-7\right)$ or/and $\mathrm{Co}\left(\mathrm{NO}_{3}\right)_{2} \cdot 6 \mathrm{H}_{2} \mathrm{O}$ (Panreac, CAS: $10026-22-9]$ and $11.37 \mathrm{~g}$ of urea (Alfa Aesar, CAS: 57-13-6), for a total metallic charge of $10 \%$ and different $x \mathrm{Ni} /(10-\mathrm{x})$ Co ratio $(x=0,2,5,8,10)$. After this time, the resulting solution was filtered and washed with distilled water, dried at $110{ }^{\circ} \mathrm{C}$ and calcined on static air for 3 hours at $550{ }^{\circ} \mathrm{C}$.

\subsection{Catalytic test}

SRE catalytic tests were performed over $100 \mathrm{mg}$ of catalyst held in a tubular quartz reactor. Samples were pre-reduced in hydrogen at $750{ }^{\circ} \mathrm{C}$ for 1 hour using a heating ramp of $10{ }^{\circ} \mathrm{C} \cdot \min -1$ and reaction was carried out at $500{ }^{\circ} \mathrm{C}$ by injecting 0.02 $\mathrm{mL} \cdot \mathrm{min}-1$ of a $\mathrm{H}_{2} \mathrm{O} / \mathrm{EtOH}$ solution (3.7 molar ratio) and $100 \mathrm{~mL} \cdot \mathrm{min}^{-1}$ of helium as carrier gas. Products were analyzed by gas chromatography using an Agilent's 490 microGC equipment, connected on-line with the reactor, provided with three columns and TCD detectors: two molecular sieves for the analysis of lighter molecules as $\mathrm{H}_{2}, \mathrm{CO}$, $\mathrm{CH}_{4}$ and $\mathrm{CO}$, and a capillary column (PoraPLOT-U) for the analysis of $\mathrm{CO}_{2}, \mathrm{H}_{2} \mathrm{O}$, ethanol and acetaldehyde. Quantitative calculations were as follows:

\section{Ethanol conversion (\%):}




$$
\mathrm{X}_{\mathrm{EtOH}}=\frac{F_{\text {EtOH }}-F_{\text {EtOH }}}{F_{\text {EtOH }}} \cdot 100
$$

being $F_{E t O H i n}$ and $F_{E t O H o u t}$ the ethanol molar flow in the inlet and outlet gas, respectively.

Selectivity to different products (\%):

$$
\mathrm{S}_{\mathrm{i}}=\frac{F_{\mathrm{i}_{\text {out }}}}{c_{\mathrm{i}}\left(F_{\mathrm{EtOH}} \mathrm{H}_{\mathrm{in}}-F_{\mathrm{EtOH}} \mathrm{out}\right)} \cdot 100
$$

being $F_{i}$ the component $i$ molar flow. $C_{i}$ is a stoichiometric value obtained by the equation: $c_{i}=\frac{\text { carbon atoms in } \mathrm{EtOH}}{\text { carbon atoms in } \tilde{i}}$

In the case of $\mathrm{H}_{2}$ selectivity we estimated the value given by the $\mathrm{EtOH} / \mathrm{H}_{2}$ stoichiometric relation in SRE, being $\mathrm{c}_{\mathrm{i}}=6$.

\section{3. $\mathrm{N}_{2}$-physisorption}

$\mathrm{N}_{2}$ adsorption/desorption isotherms were obtained at $-196{ }^{\circ} \mathrm{C}$ in a TRISTAR II (Micromeritics) equipment. With a minimum amount of $50 \mathrm{mg}$, each sample was pre-treated under vacuum at $150{ }^{\circ} \mathrm{C}$ prior to the adsorption/desorption experiment. Surface areas and porosity were calculated according to the BET and BJH method, respectively.

\subsection{TEM}

Transmission electron microscopy was carried out in a Philips CM200 microscope operating at $200 \mathrm{kV}$ using a copper grid coated with lacey carbon as sample support. Analysis of particle size was performed by sampling 150 particles.

\section{5. $X R D$}

Diffractogram patterns of calcined and reduced samples were obtained in a PANalytical X-Pert PRO diffractometer with a $\mathrm{Cu}$ anode $(\lambda=1.5418 \AA \mathrm{Cu} \mathrm{K} \alpha)$, using a Bragg-Brentano configuration in the $2 \theta$ range of $10-80^{\circ}$, with a step of $0.05^{\circ}$ and an effective acquisition time of $240 \mathrm{~s}$.

\section{6. $T P R$}


Temperature-programmed reduction experiments were done using a thermal conductivity detector calibrated with a commercial NiO. An estimated amount of calcined sample for consuming $100 \mu \mathrm{mol}$ of $\mathrm{H}_{2}$ was used in each case. Conventional experiments were carried out from room temperature up to $1000{ }^{\circ} \mathrm{C}$ with a heating ramp of $10^{\circ} \mathrm{C} \cdot \mathrm{min}^{-1}$. Experimental conditions were chosen to avoid peak coalescence [28]. A mass spectrometer was used to determine the evolution of gases during the reduction treatments of oxidized and post-reaction samples: $\mathrm{CH}_{4}\left(\mathrm{~m} / \mathrm{e}^{-}=15\right), \mathrm{H}_{2}\left(\mathrm{~m} / \mathrm{e}^{-}\right.$ $=2)$ and $\mathrm{H}_{2} \mathrm{O}\left(\mathrm{m} / \mathrm{e}^{-}=18\right)$.

\subsection{XPS}

X-ray photoelectron spectroscopy was performed in a VG-ESCALAB 210 equipment. Acquisition was performed in a chamber equipped with a SPECS Phoibos 100 hemispheric analyzer at $10^{-9}$ Torr using an anticathode of $\mathrm{MgK \alpha}(\mathrm{E}=1.5418 \mathrm{eV})$ with $12 \mathrm{kV}$ of potential acceleration and $20 \mathrm{~mA}$ of current. Catalytic systems were analyzed as-prepared and after different, consecutive in situ treatments:

1. $5 \% \mathrm{H}_{2} / \mathrm{Ar}$ at $750{ }^{\circ} \mathrm{C}$ during 1 hour with a heating ramp of $10^{\circ} \mathrm{C} \cdot \mathrm{min}^{-1}$.

2. SRE conditions at $500{ }^{\circ} \mathrm{C}$ during 1 hour by bubbling an ethanol/water solution with $100 \mathrm{~mL} \cdot \mathrm{min}^{-1}$ of argon for obtaining a similar flow gas composition as the catalytic test.

3. Hydrogen treatment with $5 \% \mathrm{H}_{2} / \mathrm{Ar}$ at $400{ }^{\circ} \mathrm{C}$, during 1 hour.

4. Hydrogen treatment with $5 \% \mathrm{H}_{2} / \operatorname{Ar}$ at $550{ }^{\circ} \mathrm{C}$, during 1 hour.

5. Hydrogen treatment with $5 \% \mathrm{H}_{2} / \operatorname{Ar}$ at $600{ }^{\circ} \mathrm{C}$, during 1 hour.

\subsection{XAS}

X-ray absorption spectra were carried out at the BL22 CLAESS beamline at the ALBA synchrotron facility (Spain). Pelletized samples were analyzed in transmission mode in an in situ cell for gas-solid reactions with an amount of sample estimated to maximize the signal/noise ratio. Due to beamtime limitations, only monometallic samples were studied. These catalytic systems were analyzed as-prepared and after different in situ treatments:

1. $5 \% \mathrm{H}_{2} / \mathrm{Ar}$ at $750{ }^{\circ} \mathrm{C}$ during 1 hour with a heating ramp of $10^{\circ} \mathrm{C} \cdot \mathrm{min}^{-1}$. 
2. SRE conditions at $500^{\circ} \mathrm{C}$ during 1 hour by bubbling an ethanol/water solution with $100 \mathrm{~mL} \cdot \mathrm{min}^{-1}$ of argon for obtaining a similar flow gas composition as the catalytic test.

Standard nickel and cobalt foils were measured and used for energy calibration. XAS spectra were recorded from 7600 to $9200 \mathrm{eV}$ (including both $\mathrm{Ni}$ and Co K-edge energies).

\section{Results and discussion}

\subsection{Characterization of calcined and reduced catalysts}

The five catalytic systems were characterized by $\mathrm{N}_{2}$ adsorption analysis (BET, BJH), XRD, TEM, TPR and XPS. XAS spectra were just collected for the two monometallic systems. As reflected in Table 1, during the alkaline treatment with urea, all samples undergo important changes of BET surface area and mean porous size. From the original value of $738 \mathrm{~m}^{2} \cdot \mathrm{g}^{-1}$ of the pristine SBA-15, the BET of the treated solids decrease to $250-280 \mathrm{~m}^{2} \cdot \mathrm{g}^{-1}$. Simultaneously, the average pore size increases from 6.7 to $9-12 \mathrm{~nm}$. Despite this loss of surface area and porosity, the images of the calcined catalysts obtained by TEM (Figure 1) shows that the channeled structure of the SBA-15 support is preserved, with the "fibrous" structures of phyllosilicate phases generated during this treatment being visible [29-31]. The formation of $(\mathrm{NiCo})_{3} \mathrm{Si}_{2} \mathrm{O}_{5}(\mathrm{OH})_{4}$ and/or $\left(\mathrm{NiCO}_{3} \mathrm{Si}_{4} \mathrm{O}_{10}(\mathrm{OH})_{2}\right.$ phyllosilicate phases [32] can be confirmed in the XRD diagrams of Figure 2 (left) by the wide peaks appearing around 35 and $61^{\circ}$ [33], the only phases detected in the calcined samples. As it can be observed in the inset, the bimetallic samples, and in particular the $5 \mathrm{Ni}-5 \mathrm{Co} / \mathrm{SBA}-15$, only show one peak near $61^{\circ}$, indicating the formation of a bimetallic nickel cobalt phyllosilicate phase.

According to the TPR profiles included in Figure 3, the 10Ni/SBA-15 catalyst presents two different reduction processes, characterized by a small shoulder at $475{ }^{\circ} \mathrm{C}$ and a main peak centered at $675{ }^{\circ} \mathrm{C}$, previously assigned to the reduction of a small amount of nickel oxide and a nickel phyllosilicate phase, respectively [29,34]. Likewise, the $10 \mathrm{Co} / \mathrm{SBA}-15$ system has the main peak at higher temperature $\left(750{ }^{\circ} \mathrm{C}\right)$ with a shoulder centered at $850{ }^{\circ} \mathrm{C}$ [26]. All the bimetallic catalysts present intermediate profiles, with the main peak centered at higher temperatures as the cobalt content 
increases. Thus, these profiles once again suggest the formation of bimetallic phases in the calcined catalysts. The diffraction diagrams of these systems reduced in hydrogen at $750{ }^{\circ} \mathrm{C}$, included in Figure 2 (right) show diffraction peaks around 44.5 and $52^{\circ}$, the result of well reduced nickel and/or cobalt phases. As detailed in the figure, the shift of these peaks with the $\mathrm{Ni} / \mathrm{Co}$ content also suggests the formation of a $\mathrm{Ni}$-Co bimetallic phase.

The TEM images of the catalytic systems obtained after hydrogen reduction are depicted in Figure 4. It can be observed how the sizes of the metallic particles are dependent on the Ni/Co ratio. Thus, the smaller particles $(4-6 \mathrm{~nm}$, black bars in Figure 5) are obtained for the $10 \mathrm{Ni} / \mathrm{SBA}-15$ catalyst, and the size progressively increases with the Co content, reaching an average value of $14.4 \mathrm{~nm}$ for the 10Co/SBA-15 (Table 1). These results clearly show a stronger interaction of nickel with the SBA-15 support, allowing a larger dispersion of the metallic phase. Additionally, both Figure 4 and 5 show that the increasing amount of cobalt gives rise to higher size heterogeneity, reaching a range around 3-25 $\mathrm{nm}$ in the monometallic 10Co/SBA-15 system.

XPS spectroscopy of these five catalysts has shed light on the origin of the observed differences in particle sizes. Figure 6a depicts the contiguous Ni $2 p$ and Co $2 p$ XPS regions of calcined samples, showing the presence of $\mathrm{Ni}^{2+}$ and $\mathrm{Co}^{2+}$ species of metal phyllosilicates, respectively [35-39]. As the nickel and cobalt contents are different in each system, the spectra are better understood when normalized to the respective $\mathrm{Ni}$ and Co contents (Figure $6 \mathrm{~b}$ ). Quantification of peaks intensities are presented in Table 2, where nominal and normalized to the metal content values is included for each catalytic system. Thus, while for calcined samples the normalized intensity of nickel remains virtually unchanged $(0.9 \pm 0.1)$, cobalt is strongly affected by the presence of nickel so that it increases the dispersion over the SBA-15 support when the amount of nickel increases. Especially striking is the high intensity of the Co $2 p$ signal obtained for $8 \mathrm{Ni}-2 \mathrm{Co} / \mathrm{SBA}-15$, more than two times the normalized value of the cobalt monometallic system (0.48 and 1.09, respectively). Anyhow, these results indicate that the smaller particle sizes obtained for the reduced nickel containing catalysts are related with the initial better dispersion of the phyllosilicate phases generated by calcination. It can be also seen in Table 2 how after reduction the intensity of $\mathrm{Ni} 2 \mathrm{p}$ peaks included in Figure 7 slightly decreases by the presence of 
cobalt $(0.25$ to 0.17$)$, while the Co $2 p$ region signals increases 3.5 times its normalized intensity when nickel is present, from 0.09 in the Co/SBA-15 to 0.31 in $8 \mathrm{Ni}-2 \mathrm{Co} / \mathrm{SBA}-$ 15. These results are in agreement with the previous characterization data indicating an important increase in the cobalt dispersion when in the bimetallic systems.

\subsection{Steam reforming of ethanol}

The catalytic performances of the five Ni-Co/SBA-15 systems were studied in the steam reforming of ethanol reaction (SRE) at $500{ }^{\circ} \mathrm{C}$ using an $\mathrm{H}_{2} \mathrm{O}: \mathrm{EtOH}$ ratio of 3.7. Table 3 includes conversion and selectivity values after $12 \mathrm{~h}$ on stream. After an initial deactivating interval of 1-2 hours, all the catalytic systems were stable without noticeable deactivation during the whole studied period under ethanol reforming conditions. As shown, ethanol conversion values range from 60 to $90 \%$, but other important differences can be noted among the five catalytic systems. Both 10Ni/SBA15 and 5Ni-5Co/SBA-15 have exactly the same behaviour in conversion and selectivity towards all products, including a $\mathrm{H}_{2} / \mathrm{CO}_{2}$ ratio near 1 . However, the $8 \mathrm{Ni}-2 \mathrm{Co} / \mathrm{SBA}-15$, with an intermediate metallic composition presents a higher conversion up to $85.6 \%$, in part due to the higher production on methane ( $21 \%$ versus $14 \%)$. This change is accompanied by the almost total disappearance of the product acetaldehyde, which had reached values close to $4 \%$ in the first two described catalysts. As this catalyst presents the higher cobalt dispersion as determined by XPS (Table 2) and a Ni/Co ratio of 4 , this singular behaviour could be related with the formation of a homogeneous well dispersed $\mathrm{Ni}_{4} \mathrm{Co}_{1}$ bimetallic phase. Finally, the $2 \mathrm{Ni}-8 \mathrm{Co} / \mathrm{SBA}-15$ and $10 \mathrm{Co} / \mathrm{SBA}-15$ are characterized by the successive increase in the selectivity to acetaldehyde ( 8.5 and $43.5 \%$, respectively), together with a parallel increase in the $\mathrm{H}_{2} / \mathrm{CO}_{2}$ ratio (1.12 and 1.42), revealing the gradual high dehydrogenation activity of these two catalytic systems $\left(\mathrm{C}_{2} \mathrm{H}_{5} \mathrm{OH} \rightarrow \mathrm{C}_{2} \mathrm{H}_{4} \mathrm{O}+\mathrm{H}_{2}\right)$. It is worth to mention that the high performance of the 10Co/SBA-15 catalyst for acetaldehyde production had been previously reported by our group as a result of the formation of a cobalt carbide phase under SRE reaction conditions [3]. Other authors also reported cobalt containing catalytic systems presenting values for acetaldehyde production with selectivity values up to $50 \%$ $[40,41]$. 


\subsection{Characterization studies after steam reforming of ethanol}

In order to clarify the origin of the different catalytic performances in the catalytic systems studied in this work, we have performed additional characterization studies after submitting the catalysts to SRE reaction conditions. Thus, after the SRE reaction the catalysts present the appearance showed in the TEM images of Figure 8. According to the analysis of particles sizes in the five systems (see histograms included in Figure 5), two different behaviors can be observed. The two systems with the higher $\mathrm{Ni}$ content essentially maintain their size and distribution of the freshly reduced $10 \mathrm{Ni}$ and $8 \mathrm{Ni}-2 \mathrm{Co} / \mathrm{SBA}-15$ catalysts. Surprisingly, the analysis of the TEM images of both catalysts with the higher cobalt content (2Ni-8Co and 10Co/SBA-15) makes it clear that the particle size decreases, which is more evident in the 10Co/SBA-15 catalyst, where no nickel is present. According to our previous findings [3], this unexpected redispersion of metallic particles could be related to the formation of a cobalt carbide phase, which apparently breaks the cobalt metallic particles, significantly reducing the particle size. In turn, this phenomenon seems to correlate with the higher acetaldehyde production observed in these two systems (Table 3). In order to deepen the origin of this phenomenon, we have carried out an in situ XPS study of the catalysts after the SRE reaction, which results are depicted in Figure 9. The comparison between the spectra before and after SRE reaction shows essentially that there are no significant changes in the $\mathrm{Ni} 2 \mathrm{p}$ region of the four $\mathrm{Ni}$-containing catalysts, except for a slight increase in the intensity for the $2 \mathrm{Ni}-8 \mathrm{Co} / \mathrm{SBA}-15$, which agrees with higher dispersion after reaction observed previously by TEM (Figure 5). In a first inspection, a similar behavior is observed in the Co $2 p$ region of the two more $\mathrm{Ni}$-enriched systems ( $8 \mathrm{Ni}-2 \mathrm{Co}$ and $5 \mathrm{Ni}-5 \mathrm{Co} / \mathrm{SBA}-15$ ), while the Co $2 \mathrm{p}$ regions of $2 \mathrm{Ni}-8 \mathrm{Co}$ and especially, 10Co/SBA-15 catalysts are clearly modified, shifting the main peak from $778.0 \mathrm{eV}$ to lower binding energy values. This red shift of cobalt to an apparently more reduced state has been previously observed by us in the monometallic catalytic system and ascribed to the formation of a new cobalt carbide phase under SRE reaction conditions. In fact, the observed peak is an envelope of two different ones coming from a mixture of cobalt carbide (centered at $776.6 \mathrm{eV}$ ) and metallic phases (centered at $778.0 \mathrm{eV}$ ) [3]. Deconvolution of this peak reveals the presence of $70 \%$ metallic cobalt, $30 \%$ cobalt carbide in the 10Co/SBA-15 catalyst, and $79 \%$ metallic cobalt, $21 \%$ 
of cobalt carbide in the $2 \mathrm{Ni}-8 \mathrm{Co} / \mathrm{SBA}-15$ catalyst. The different amounts of carbide phase detected in these catalysts could account for the different acetaldehyde production observed in these two catalytic systems (Table 3 ). In this sense, it is worth to mention that, although less obvious, even the Co $2 p$ region of $5 \mathrm{Ni}-5 \mathrm{Co} / \mathrm{SBA}-15$ presents a small red shift which can be convoluted with a $10 \%$ contribution of a cobalt carbide phase at $776.6 \mathrm{eV}$. The fact that this catalyst has the same acetaldehyde production as the $10 \mathrm{Ni} / \mathrm{SBA}-15$ indicates that there is a minimum amount of carbide needed to increase the acetaldehyde production. This could be due to the fact that the adsorption of ethanol on the cobalt surface, the first step in both reforming and dehydrogenation of ethanol, is a structure sensitive reaction [20] and therefore needing the formation of a specific ensemble of active atoms to constitute the cobalt carbide active site.

\subsection{Further characterization of carbide phase}

In order to understand the state of this carbide phase, a new set of TPR experiments have been performed. In this case, a first TPR has been recorded just up to $750{ }^{\circ} \mathrm{C}$, maintaining isothermally the same reducing conditions during $1 \mathrm{~h}$. Afterwards, the systems were submitted to SRE reaction conditions at $500{ }^{\circ} \mathrm{C}$ during 1 $\mathrm{h}$ and a second TPR recorded. The two TPR profiles are depicted in Figure 10. As expected, the profiles corresponding to the first TPR up to $750{ }^{\circ} \mathrm{C}$ (thin line) are similar to those of Figure 3. Likewise, all the profiles of the second TPRs (thick line) have two distinct parts. A first positive peak at low temperature (around $520{ }^{\circ} \mathrm{C}$ ), indicating depletion of hydrogen, which in the $10 \mathrm{Co}$ and $2 \mathrm{Ni}-8 \mathrm{Co} / \mathrm{SBA}-15$ catalysts is accompanied with a shoulder or small peak at $620^{\circ} \mathrm{C}$. Along with this, a negative peak appears at higher temperature, centred at $750{ }^{\circ} \mathrm{C}$, which must correspond to desorption of previously adsorbed hydrogen on the metallic particles. It is important to note that other processes or the formation of other products (i.e. methane) could affect the signal from the TCD detector during TPR, which will be discussed below. Thus, the hydrogen consumption process observed at low temperature (525 ㄷ) could be due to the reduction of metal particles previously oxidized during the SRE reaction. This possibility has been discarded in view of the results obtained by XAS spectroscopy under similar SRE reaction conditions (Figure 11). As shown in XANES and Fourier 
Transform curves, after reaction, both nickel and cobalt remain completely reduced. Thus, the depletion of hydrogen only can be due to reduction of carbon deposited during the SRE reaction, which can be confirmed in Figure 12, where are depicted the TCD and mass spectrometer profiles obtained during the second TPR. Methane $\left(\mathrm{m} / \mathrm{e}^{-}\right.$ $=15)$ is formed coinciding with the depletion of hydrogen $\left(m / e^{-}=2\right)$, confirming that carbon is eliminated in this low temperature process.

However, a deeper comparison of the profiles of the five catalysts shows once again two different patterns. On the one hand, in the three catalysts with the high amount of nickel (10Ni, $8 \mathrm{Ni}-2 \mathrm{Co}$ and $5 \mathrm{Ni}-5 \mathrm{Co} / \mathrm{SBA}-15)$ the peak maxima for $\mathrm{H}_{2}$ and $\mathrm{CH}_{4}$ approximately appear at the same temperature $\left(521,527\right.$ and $529 \pm 3{ }^{\circ} \mathrm{C}$, respectively), and consist in asymmetric peaks with a soft tail a high temperature. But the profiles for the two Co-enriched catalysts follow a different pattern. In both cases (10Co and $2 \mathrm{Ni}$ 8Co/SBA-15) the $m / e^{-}=2$ peak coming from $\mathrm{H}_{2}$ species is complex, with at less two maxima at different temperatures $\left(528\right.$ and $625{ }^{\circ} \mathrm{C}$ for $10 \mathrm{Co} / \mathrm{SBA}-15 ; 528$ and $610{ }^{\circ} \mathrm{C}$ for $2 \mathrm{Ni}-8 \mathrm{Co} / \mathrm{SBA}-15)$. Moreover, maxima for $\mathrm{H}_{2}$ and $\mathrm{CH}_{4}$ do not match, with the maxima for methane appearing at a temperature $35{ }^{\circ} \mathrm{C}$ higher. The fact that in these two systems the higher methane production does not match the higher hydrogen consumption must indicate that the methane formed during the TPR comes from a different carbon phase, more hydrogenated and therefore consuming less hydrogen. As this effect, much more intense in the cobalt monometallic system, correlates with the amount of cobalt carbide phase in these two systems, it could be due to the hydrogenation of this carbide phase, which is thermodynamically unstable [42], and could adsorb a certain amount of hydrogen before decompose $\left(\mathrm{CoC}_{x}+\mathrm{H}_{2} \rightarrow \mathrm{Co}^{0}+\right.$ $\left.\mathrm{CH}_{4}\right)$.

If this were the case, a hydrogen treatment of the catalysts presenting the cobalt carbide phase should reverse the red shift of the Co $2 p$ peak observed by XPS. As shown in Figure 13, this is really what happens when the 10Co/SBA-15 catalyst is treated under SRE conditions and later in hydrogen at increasing temperatures up to $600{ }^{\circ} \mathrm{C}$, the higher reachable in our XPS equipment. The SRE treatment causes the red shift of the Co $2 p$ peak, which does not move significantly when treated in hydrogen till $550{ }^{\circ} \mathrm{C}$. At higher temperature, a blue shift is observed, indicating that the carbide phase is decomposing and the metallic cobalt restored. 


\section{Conclusions}

We have characterized five $\mathrm{Ni}-\mathrm{Co} / \mathrm{SBA}-15$ bimetallic systems active in the steam reforming of ethanol reaction at $500{ }^{\circ} \mathrm{C}$. The presence of nickel favors the dispersion of metallic phases after reduction, while the cobalt tends to generate larger metallic particles. However, these Co-enriched particles significantly reduce their size after SRE reaction, and in parallel, the higher cobalt content increases the acetaldehyde production. Both effects, high acetaldehyde production and breakage of metallic particles can be explained accepting the formation of a cobalt carbide phase, which although thermodynamically metastable, has proved to remain stable under hydrogen at $550{ }^{\circ} \mathrm{C}$.

\section{Acknowledgments}

We thank the "Ministerio de Economia and Competitividad" of Spain (Projects CTQ2014-60524-R and ENE2017-88818-C2-1-R) and the ESRF facility and staff (BM25 SPLINE beamline), and the ALBA facility and staff (BL22 CLAESS beamline) for their experimental support. A.R.G thanks also the Spanish Government for the PhD fellowship (BES-2012-061744).

\section{References}

1. Oyama, S. T.; Hacarlioglu, P.; Gu, Y. F.; Lee, D. Int. J. Hydrogen Energy 2012, 37, 10444-10450.

2. Bhavani, A. G.; Kim, W. Y.; Lee, J. S. ACS Catal. 2013, 3, 1537-1544.

3. Rodriguez-Gomez, A.; Holgado, J. P.; Caballero, A. ACS Catal. 2017, 7, 5243-5247.

4. Huber, G. W.; Iborra, S.; Corma, A. Chem. Rev. 2006, 106, 4044-4098.

5. Tanksale, A.; Beltramini, J. N.; Lu, G.Q. M. Renewable Sustainable Energy Rev. 2010, $14,166-182$.

6. Sharma, Y. C.; Kumar, A.; Prasad, R.; Upadhyay, S. N. Renewable Sustainable Energy Rev. 2017, 74, 89-103. 
7. Wu, C.; Dupont, V.; Nahil, M. A. ; Dou, B. ; Chen, H.; Williams, P. T. Journal of the Energy Institute 2017, 90, 276-284.

8. Chen, J.; Sun, J.; Wang, Y. Ind. Eng. Chem. Res. 2017, 56, 4627-4637.

9. Palma, V.; Castaldo, F.; Ciambelli, P.; Iaquaniello, G. Appl Catal B: Environmental 2014, 145, 73-84.

10. Ito, S-i.; Tomishige, K. Catal Commun. 2010, 12, 157-160.

11. Divins, N. J.; Casanovas, A.; Xu, W.; Senanayake, S. D. ; Wiater, D. ; Trovarelli, A. ; Llorca, J. Catal Today 2015, 253, 99-105.

12. Su, S. ; Li, W. ; Bai, Z. ; Xiang, H. Int. J. Hydrog. Energy 2008, 33, 6947-6952.

13. Goula, M. A. ; Kontou, S. K. ; Tsiakaras, P. E. Appl. Catal B: Environmental 2004, 49, 135-144.

14. Hou, T. F.; Yu, B.; Zhang, S. Y.; Xu, T. K.; Wang, D. Z.; Cai, W. J. Catal. Commun. 2015, 58, 137-140.

15. Song, H.; Ozkan, U. S. J. Phys. Chem. A 2010, 114, 3796-3801.

16. El Doukkali, M.; Iriondo, A.; Arias, P. L.; Cambra, J. F.; Gandarias, I.; Barrio, V. L. Int. J. Hydrog. Energy 2012, 37, 8298-8309.

17. Barroso, M. N.; Galetti, A. E.; Abello, M. C. Appl. Catal. A: General 2011, 394, 124131.

18. Profeti, L. P. R.; Ticianelli, E. A.; Assaf, E. M. J. Power Sources 2008, 175, 482-489.

19. Duan, S.; Senkan, S. Ind. Eng. Chem. Res. 2005, 44, 6381-6386.

20. Parlett, C. M. A.; Aydin, A.; Durndell, L. J.; Frattini, L.; Isaacs, M. A.; Lee, A. F. ;

Liu, X.; Olivi, L.; Trofimovaite, R.; Wilson, K.; Wu, C. Catal. Commun. 2017, 91, 76-79.

21. Mattos, L. V.; Jacobs, G.; Davis, B. H.; Noronha, F. B. Chem. Rev. 2012, 112, 40944123.

22. Gonzalez-Delacruz, V. M.; Pereñiguez, R.; Ternero, F.; Holgado, J. P.; Caballero, A. J. Phys. Chem. C 2012, 116, 2919-2926.

23. Zhang, J.; Wang, H.; Dalai, A. K. J. Catal. 2007, 249, 300-310.

24.Wang, L.; Li, D.; Koike, M.; Watanabe, H.; Xu, Y.; Nakagawa, Y.; Tomishige, K. Fuel 2013, 112, 654-661.

25. Silva, C. R. B.; Conceicao, L.; Ribeiro, N. F. P.; Souza, M. M. V. M. Catal. Commun. 2011, 12, 665-668. 
26. Rodriguez-Gomez, A.; Pereñiguez, R.; Caballero, A. Catal. Today 2017, DOI: 10.1016/j.cattod.2017.02.020.

27. Zhao, D. Y.; Feng, J. L.; Huo, Q. S.; Melosh, N.; Fredrickson, G. H.; Chmelka, B. F.; Stucky, G. D. Science 1998, 279, 548-552.

28. Malet, P.; Caballero, A. Chem. Soc. Faraday Trans., 1988, 84, 2369-2375.

29. Rodriguez-Gomez, A.; Caballero, A. ChemNanoMat 2017, 3, 94-97.

30. Kong, X. ; Zhu, Y. ; Zheng, H. ; Li, X. ; Zhu, Y. ; Li, Y. ACS Catal. 2015, 5, 5914-5920.

31. Zhang, C. ; Yue, H. ; Huang, Z. ; Li, S. ; Wu, G. ; Ma, X. ; Gong, J. ACS Sustain. Chem. Eng. 2012, 1, 161-173.

32. Kim, J. S.; Park, I.; Jeong, E.; Jin, K.; Seong, W. M.; Yoon, G.; Kim, H.; Kim, B.; Nam, K. T.; Kang, K. Adv. Mater. 2017, 29, 1606893.

33. Galvez, M. E.; Albarazi, A.; Da Costa, P. Appl. Catal. A: General 2015, 504, 143-150.

34. Rodriguez-Gomez, A.; Pereñiguez, R.; Caballero, A. J. Phys.Chem B 2017, DOI: 10.1021/acs.jpcb.7b03835.

35. Espinos, J. P.; Gonzalez-Elipe, A. R.; Caballero, A.; Garcia, J.; Munuera, G. J. Catal. $1992,136,415-422$.

36. Lu, B.; Ju, Y.; Abe, T.; Kawamoto, K. RSC Adv. 2015, 5, 56444-56454.

37. Todorova, S.; Kadinov, G.; Tenchev, K.; Kalvachev, Y.; Kostov-Kytin, V. J. Mater. Sci. 2007, 42, 3315-3320.

38. Kengne, B. F.; Alayat, A. M.; Luo, G.; McDonald, A. G.; Brown, J.; Smotherman, H.; Mcllroy, D. N. Appl. Surf Sci. 2015, 359, 508-514.

39. Todorova, S.; Naydenov, A.; Kolev, H.; Holgado, J. P.; Ivanov, G.; Kadinov, G.; Caballero, A. Appl. Catal. A: General 2012, 413, 43-51.

40. Llorca, J.; Ramirez de la Piscina, P.; Dalmon, J.-A.; Homs, N. Chem. Mater. 2004, 16, 3573-3578.

41. Vizcaíno, A. J.; Carrero, A.; Calles, J. A. Fuel Process. Technol. 2016, 146, 99-109.

42. Zhao, Y. H.; Su, H. Y.; Sun, K.; Liu, J.; Li, W. X. Surf. Sci. 2012, 606, 598-604. 
Table 1

Characterization data of the Ni-Co/SBA-15 catalytic systems.

\begin{tabular}{|c|c|c|c|c|c|}
\hline & $\begin{array}{c}S_{B E T} \\
\left(m^{2} \cdot g^{-1}\right)\end{array}$ & $\begin{array}{c}\text { Average } \\
\text { pore } \\
\text { size } \\
(\mathrm{nm})^{\mathrm{a}}\end{array}$ & $\begin{array}{c}\mathrm{Ni} / \mathrm{Co}_{\text {surf. }} \\
\text { by XPS } \\
\left(\%_{\text {at }}\right)\end{array}$ & $\begin{array}{c}\text { Crystallite } \\
\text { size } \\
\left(X^{b} D^{b}\right) \\
\text { [Calc/Red] }\end{array}$ & $\begin{array}{c}\text { Average } \\
\text { metallic } \\
\text { particle size } \\
\text { (TEM ') } \\
\text { [Red/SRE] }\end{array}$ \\
\hline SBA-15 & 738 & 6.7 & - & - & - \\
\hline $\begin{array}{l}\text { SBA-15 } \\
\text { treated with urea }\end{array}$ & 249 & 9.1 & - & - & - \\
\hline 10Ni/SBA-15 & 283 & 10.3 & $11.3 / 0.0$ & $5.4 / 4.1$ & $4.3 / 4.2$ \\
\hline 8Ni-2Co/SBA-15 & 272 & 11.1 & $7.8 / 2.6$ & 7.6/4.1 & $4.4 / 4.0$ \\
\hline 5Ni-5Co/SBA-15 & 261 & 12.0 & $4.2 / 3.1$ & $7.0 / 4.5$ & $5.9 / 8.6$ \\
\hline 2Ni-8Co/SBA-15 & 269 & 10.3 & $1.9 / 7.1$ & $6.5 / 8.2$ & $8.6 / 7.0$ \\
\hline 10Co/SBA-15 DP & 280 & 9.8 & $0.0 / 7.1$ & $5.1 / 13.2$ & $14.4 / 9.6$ \\
\hline
\end{tabular}

${ }^{\mathrm{a}}$ Obtained by the BJH method.

${ }^{\mathrm{b}}$ Calculated from the Scherrer equation.

c Obtained by sampling 150 particles. 
Table 2

Atomic percentage of $\mathrm{Ni}$ and/or Co as determined from XPS signals

\begin{tabular}{|l|c|c|c|c|}
\hline & \multicolumn{2}{|c|}{ Calcined catalysts } & \multicolumn{2}{c|}{ Reduced catalysts } \\
\cline { 2 - 5 } & At\% Ni (N\%) & At\% Co (N\%) & At\% Ni (N\%) & At\% Co (N\%)* \\
\hline 10Ni/SBA-15 & $10.89(1.09)$ & - & $2.5(0.25)$ & - \\
\hline 8Ni-2Co/SBA-15 & $7.88(0.99)$ & $2.18(1.09)$ & $2.2(0.28)$ & $0.61(0.31)$ \\
\hline 5Ni-5Co/SBA-15 & $4.17(0.83)$ & $3.80(0.76)$ & $0.73(0.15)$ & $0.75(0.15)$ \\
\hline 2Ni-8Co/SBA-15 & $1.83(0.91)$ & $7.14(0.89)$ & $0.33(0.17)$ & $0.59(0.07)$ \\
\hline 10Co/SBA-15 & - & $4.78(0.48)$ & - & $0.9(0.09)$ \\
\hline
\end{tabular}

${ }^{*} \mathrm{~N} \%$ : atomic percentage normalized to nominal Ni/Co metal content (10-8\%) 
Table 3

Catalytic performances in Steam Reforming of Ethanol after $12 \mathrm{~h}$ of TOS

\begin{tabular}{|c|c|c|c|c|c|c|c|}
\hline & \multirow{2}{*}{$\begin{array}{c}\text { Conv. } \\
\text { (\%) }\end{array}$} & \multirow[b]{2}{*}{$\mathbf{H}_{2}$} & \multirow[b]{2}{*}{$\mathrm{CO}_{2}$} & \multicolumn{4}{|c|}{ Selectivities (\%) } \\
\hline & & & & $\mathrm{H}_{2} / \mathrm{CO}_{2}$ & $\mathrm{CO}$ & $\mathrm{CH}_{4}$ & $\mathrm{CH}_{3} \mathrm{CHO}$ \\
\hline 10Ni/SBA-15 & 69.3 & 59.4 & 59.5 & 1.00 & 19.6 & 13.8 & 3.8 \\
\hline 8Ni2Co/SBA-15 & 85.6 & 62.4 & 60.3 & 1.03 & 18.3 & 21.0 & 0.1 \\
\hline $5 \mathrm{Ni} 5 \mathrm{Co} / \mathrm{SBA}-15$ & 68.0 & 62.2 & 60.9 & 1.02 & 19.1 & 14.0 & 4.4 \\
\hline 2Ni8Co/SBA-15 & 59.3 & 70.1 & 62.6 & 1.12 & 14.2 & 14.9 & 8.5 \\
\hline Co/SBA-15 & 88.6 & 55.1 & 38.9 & 1.42 & 14.1 & 3.7 & 43.5 \\
\hline
\end{tabular}




\section{Figure Captions}

Figure 1. TEM images for calcined 10Ni/SBA-15 (a), 8Ni-2Co/SBA-15 (b), 5Ni-5Co/SBA15 (c), 2Ni-8Co/SBA-15 (d) and 10Co/SBA-15 (e) catalysts.

Figure 2. XRD patterns for (left) calcined and (right) treated in $5 \% \mathrm{H}_{2} / \mathrm{Ar}$ at $750{ }^{\circ} \mathrm{C}$ nickel-cobalt-based systems.

Figure 3. Temperature-programmed reduction profiles for the calcined $\mathrm{Ni}-\mathrm{Co} / \mathrm{SBA}-15$ catalytic systems.

Figure 4. TEM images of 10Ni/SBA-15 (a), 8Ni-2Co/SBA-15 (b), 5Ni-5Co/SBA-15 (c), 2Ni$8 \mathrm{Co} / \mathrm{SBA}-15(\mathrm{~d})$, and $10 \mathrm{Co} / \mathrm{SBA}-15(\mathrm{e})$, after hydrogen reduction at $750{ }^{\circ} \mathrm{C}$.

Figure 5. Histograms of particle sizes for 10Ni/SBA-15 (a), 8Ni-2Co/SBA-15 (b), 5Ni5Co/SBA-15 (c), 2Ni-8Co/SBA-15 (d), and 10Co/SBA-15 (e), after reduction (black bars) and after being submitted to SRE reaction conditions (red bars).

Figure 6. XPS spectra of calcined Ni-Co/SBA-15 systems (a) and same spectra normalized to metal percentage (b).

Figure 7. XPS spectra of reduced Ni-Co/SBA-15 systems normalized to metal percentage.

Figure 8. TEM images for 10Ni/SBA-15 (a), 8Ni-2Co/SBA-15 (b), 5Ni-5Co/SBA-15 (c), 2Ni-8Co/SBA-15 (d), and 10Co/SBA-15 (e), after SRE reaction.

Figure 9. XPS spectra of reduced (thin line) and spent (thick line) Ni-Co/SBA-15 systems normalized to metal percentage.

Figure 10. TPR profiles of Ni-Co/SBA-15 catalysts up to $750{ }^{\circ} \mathrm{C}$ plus $1 \mathrm{~h}$ isotherm. Thin line: first TPR. Thick line: second TPR after SRE reaction.

Figure 11. Co (left) and Ni (right) K-edge XANES spectra and Fourier transform functions of the EXAFS oscillations after different treatments.

Figure 12. TCD and Mass Spectrometer signals coming from $\mathrm{H}_{2}\left(\mathrm{~m} / \mathrm{e}^{-}=2\right)$ and methane $\left(\mathrm{m} / \mathrm{e}^{-}=15\right)$ for $10 \mathrm{Ni} / \mathrm{SBA}-15$ (a), 8Ni-2Co/SBA-15 (b), 5Ni-5Co/SBA-15 (c), 2Ni-8Co/SBA15 (d), and 10Co/SBA-15 (e).

Figure 13. XPS spectra of reduced, spent and hydrogenated 10Co/SBA-15 system. 

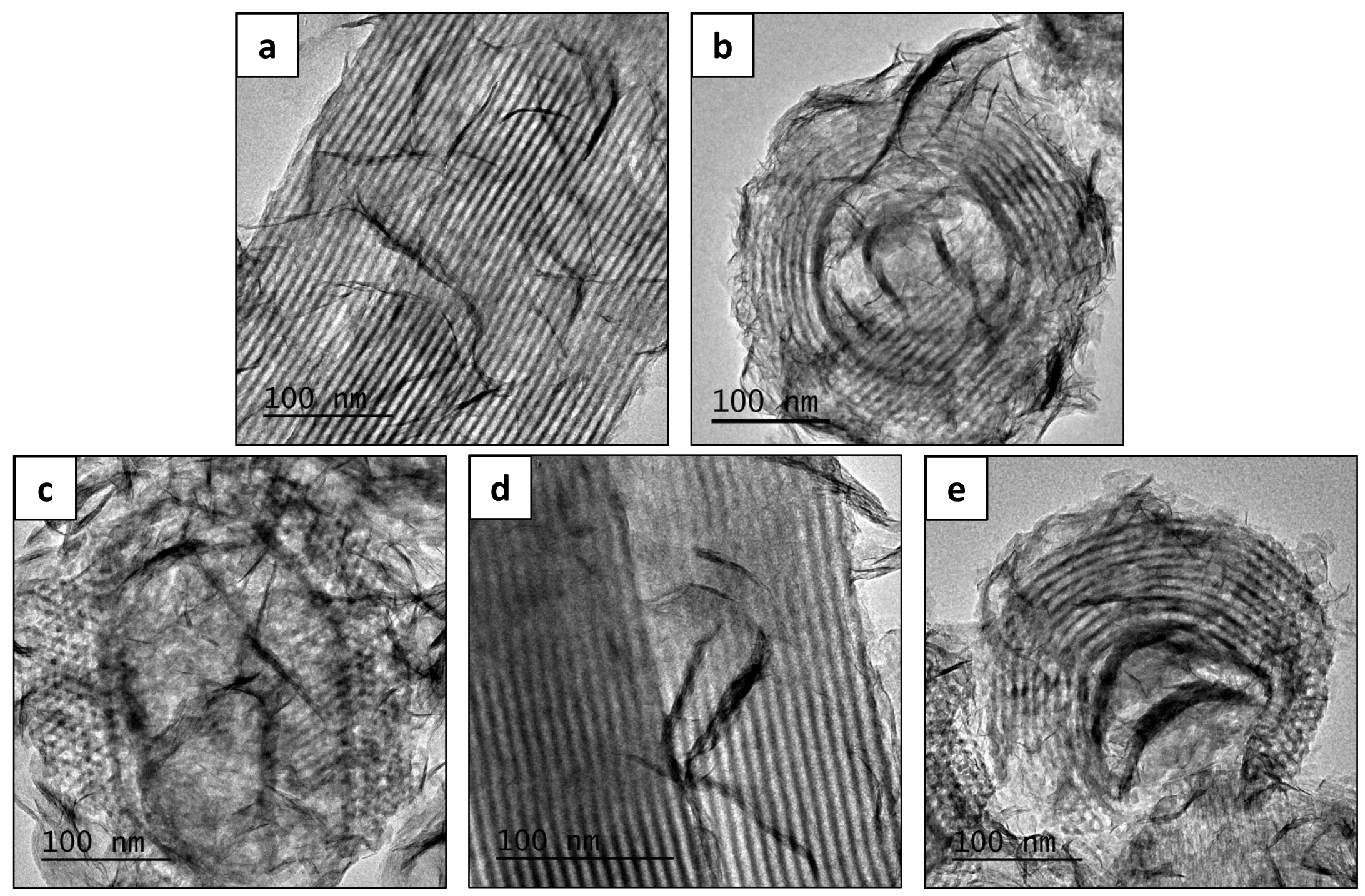

Figure 1. TEM images for calcined 10Ni/SBA-15 (a), 8Ni-2Co/SBA-15 (b), 5Ni-5Co/SBA-15 (c), $2 \mathrm{Ni}-8 \mathrm{Co} / \mathrm{SBA}-15(\mathrm{~d})$ and 10Co/SBA-15 (e) catalysts. 

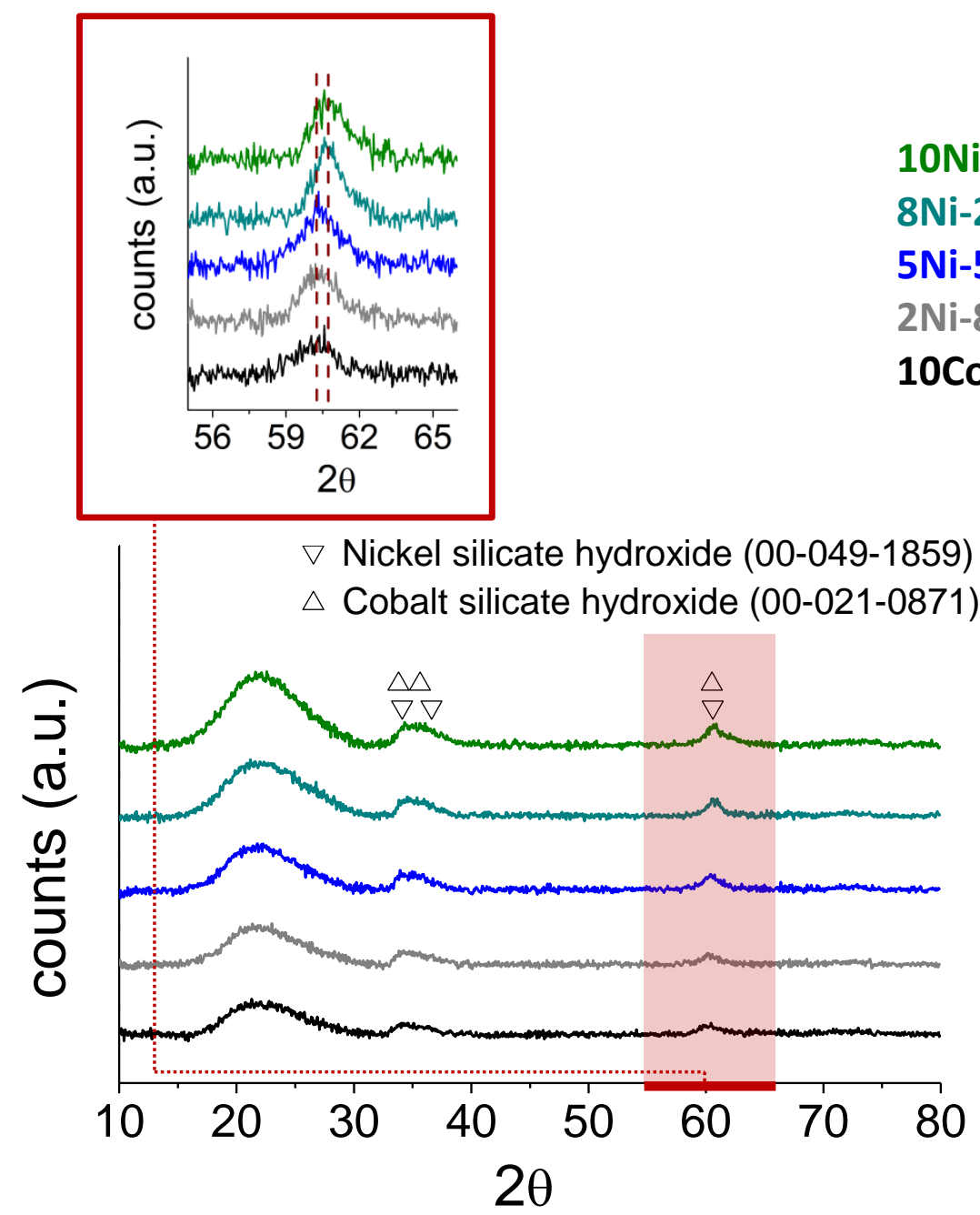

10Ni/SBA-15

8Ni-2Co/SBA-15

5Ni-5Co/SBA-15

2Ni-8Co/SBA-15

10Co/SBA-15
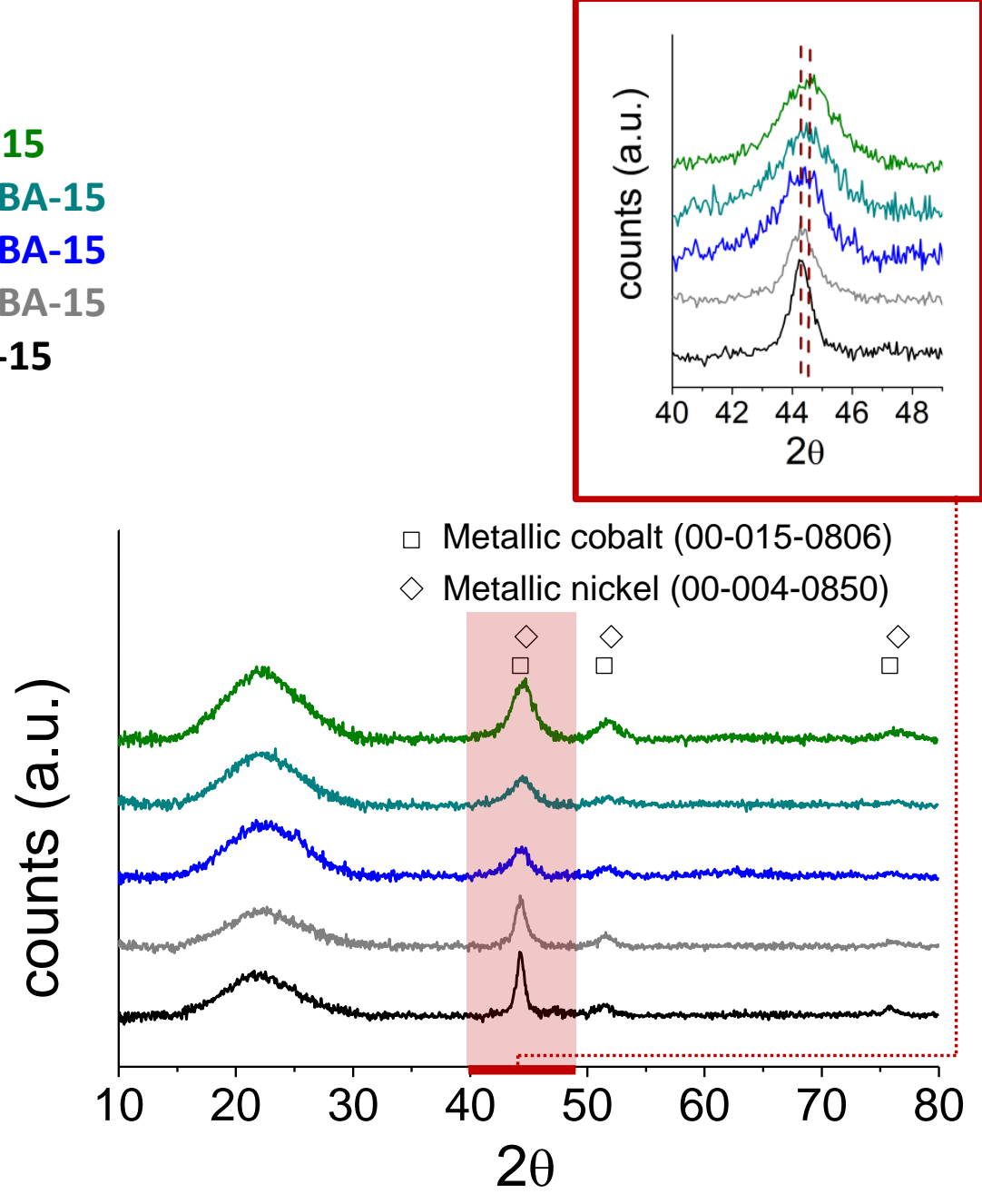

Figure 2. XRD patterns for (left) calcined and (right) treated in $5 \% \mathrm{H}_{2} / \mathrm{Ar}$ at $750{ }^{\circ} \mathrm{C}$ nickel-cobalt-based systems. 


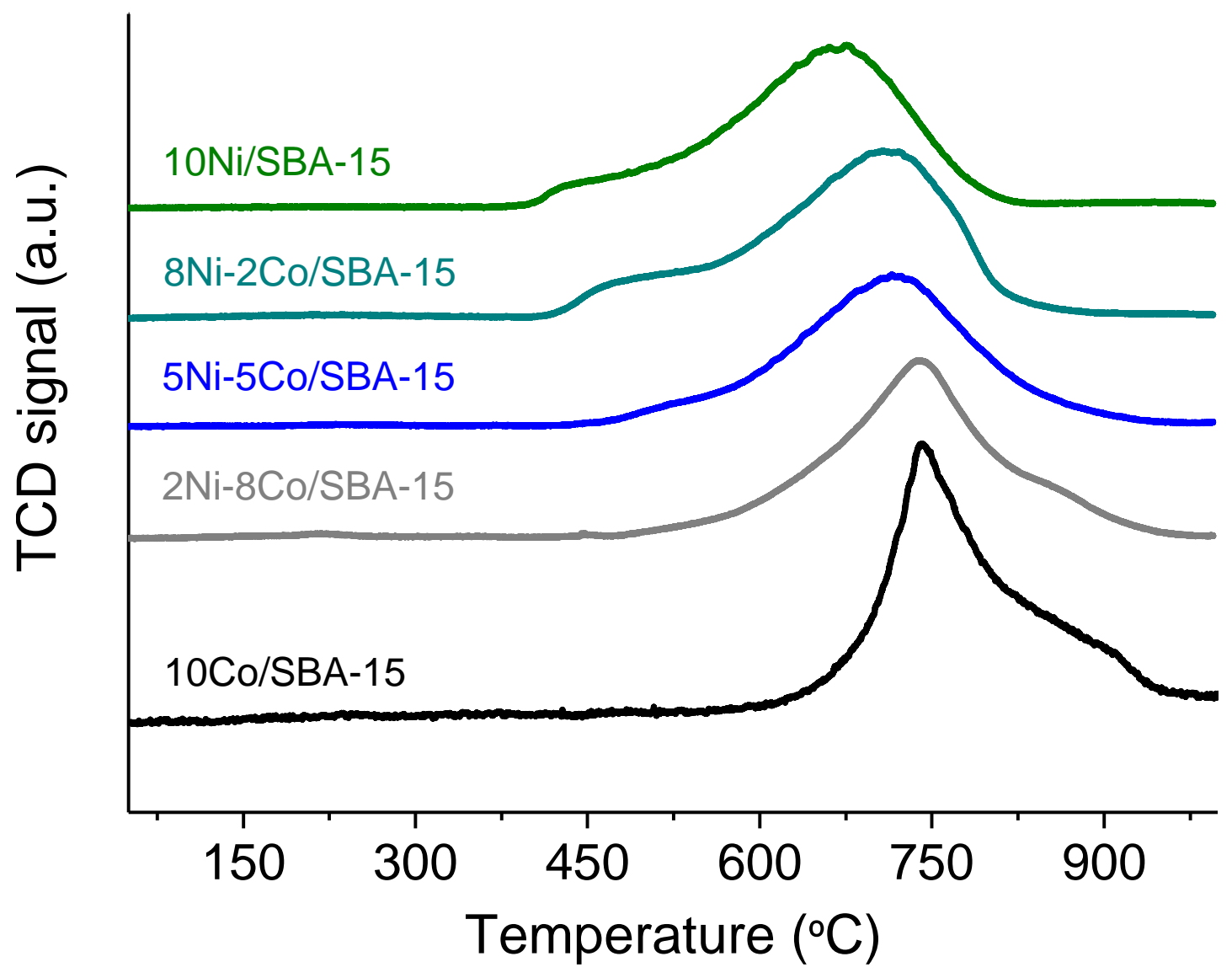

Figure 3. Temperature-programmed reduction profiles for the calcined $\mathrm{Ni}-\mathrm{Co} / \mathrm{SBA}-15$ catalytic systems. 


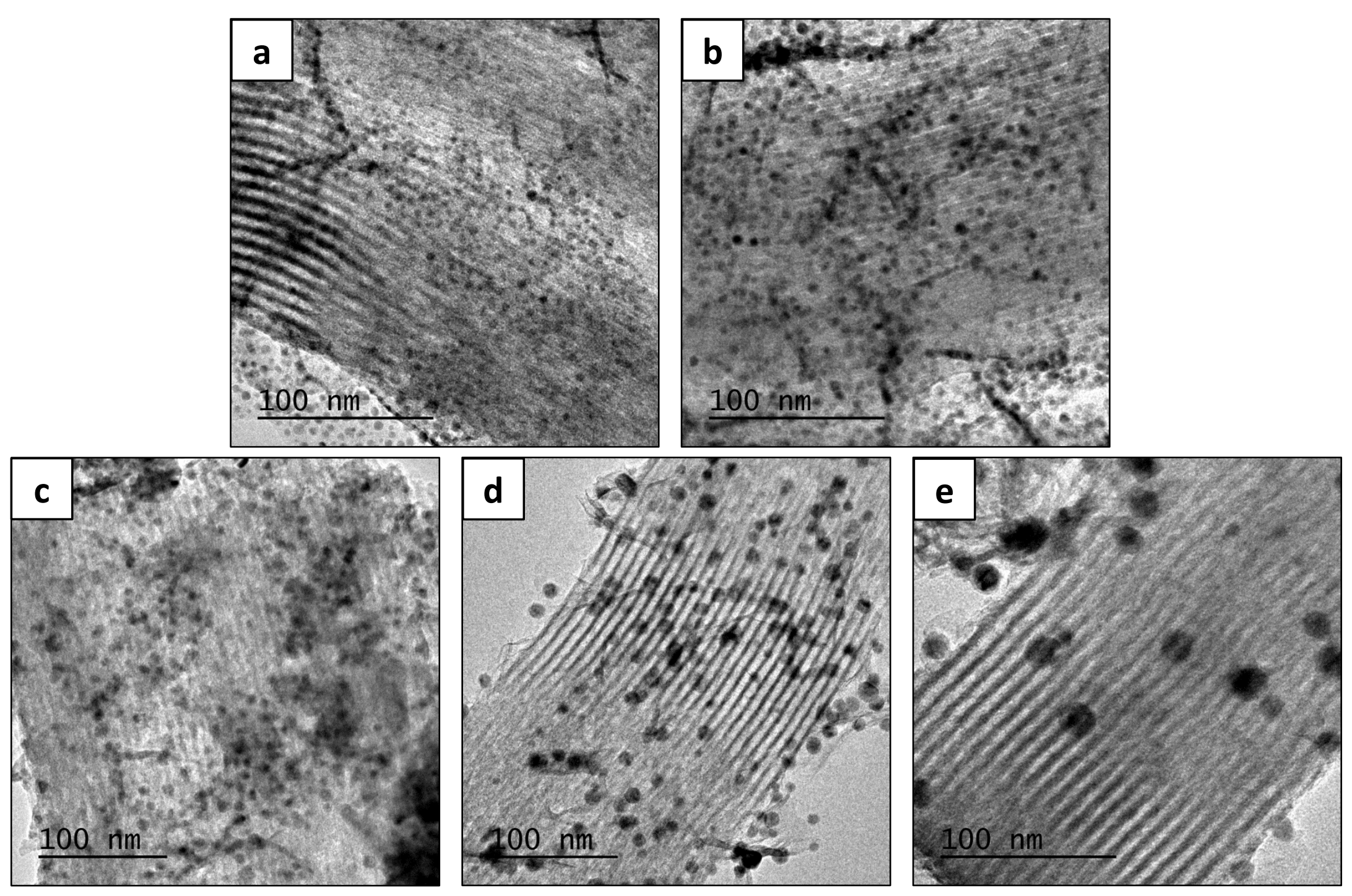

Figure 4. TEM images of 10Ni/SBA-15 (a), 8Ni-2Co/SBA-15 (b), 5Ni-5Co/SBA-15 (c), $2 \mathrm{Ni}-$ $8 \mathrm{Co} / \mathrm{SBA}-15$ (d), and 10Co/SBA-15 (e), after hydrogen reduction at $750{ }^{\circ} \mathrm{C}$. 

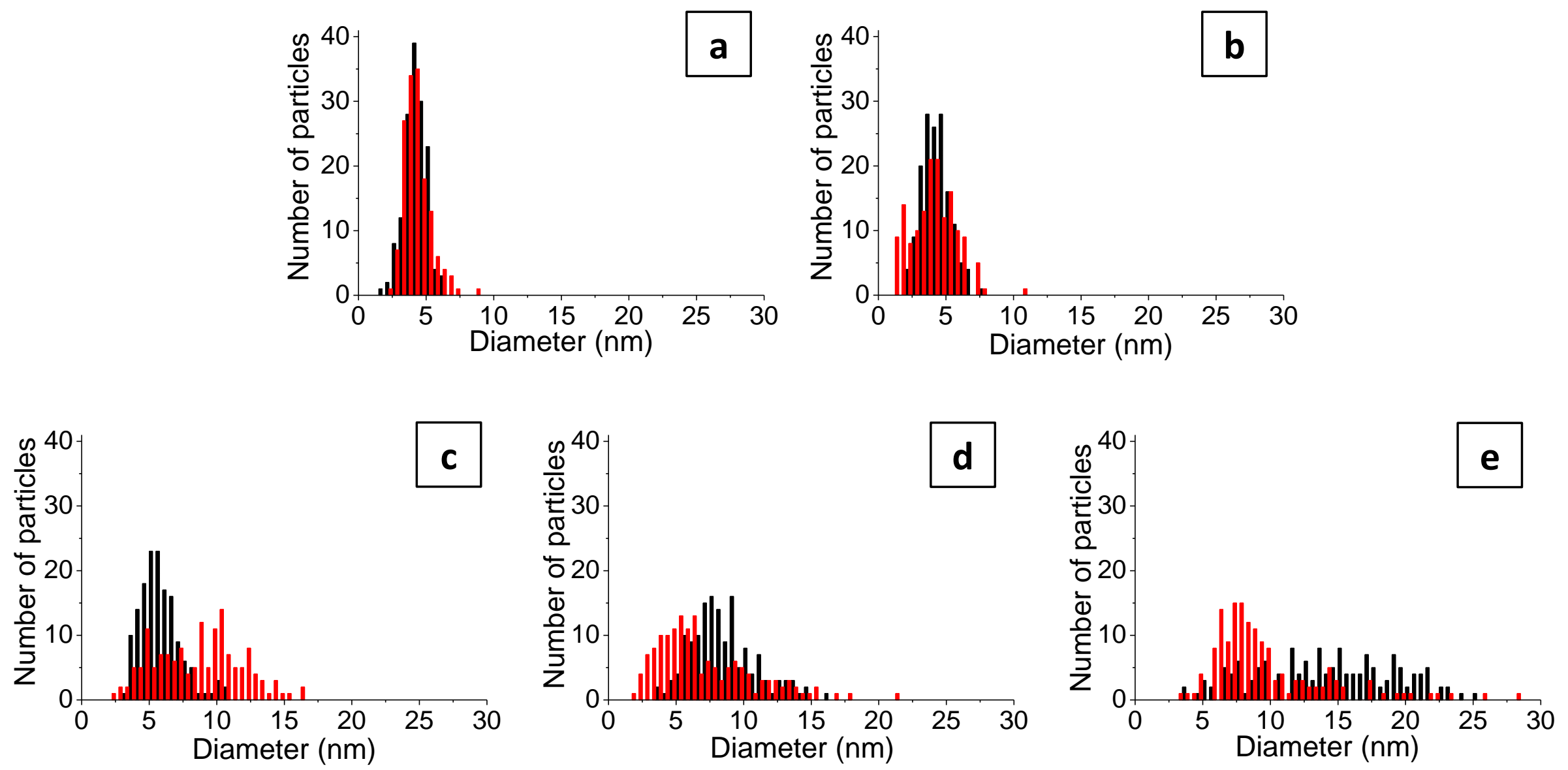

Figure 5. Histograms of particle sizes for 10Ni/SBA-15 (a), 8Ni-2Co/SBA-15 (b), 5Ni-5Co/SBA15 (c), 2Ni-8Co/SBA-15 (d), and 10Co/SBA-15 (e), after reduction (black bars) and after being submitted to SRE reaction conditions (red bars). 

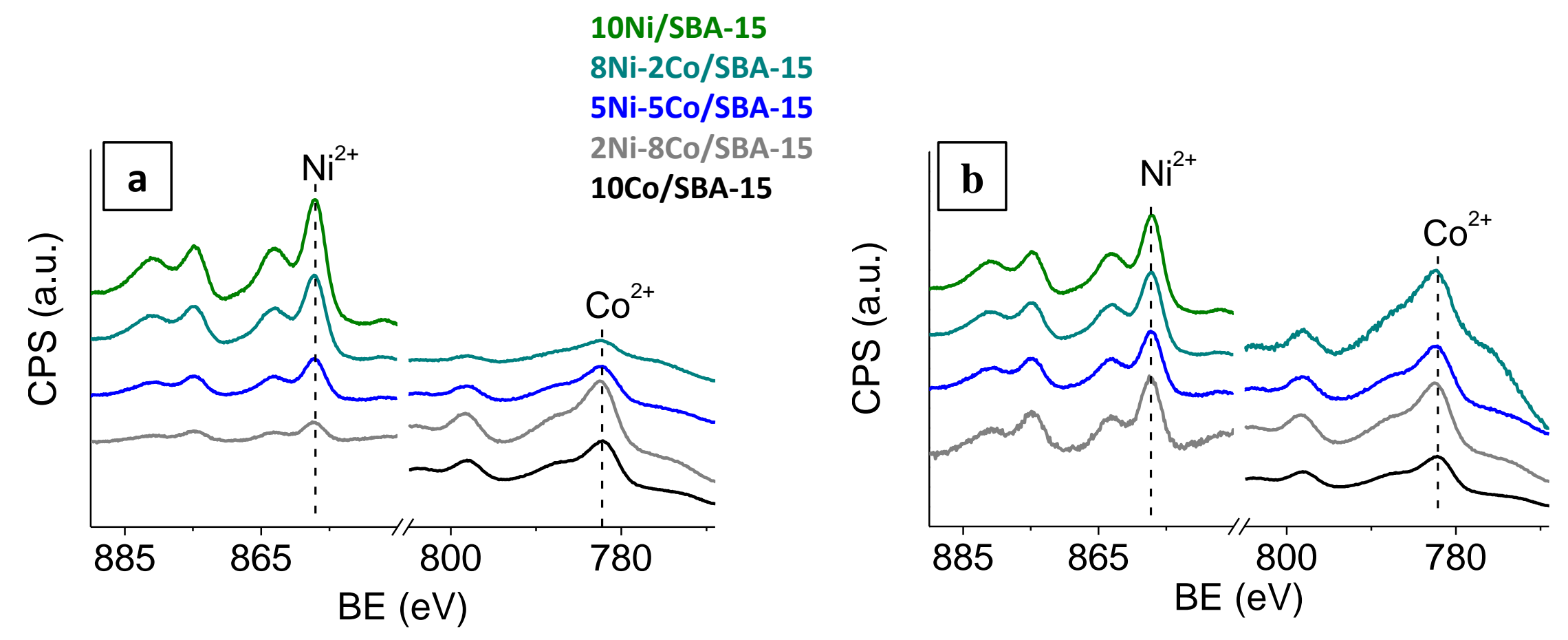

Figure 6. XPS spectra of calcined Ni-Co/SBA-15 systems (a) and same spectra normalized to metal percentage (b). 


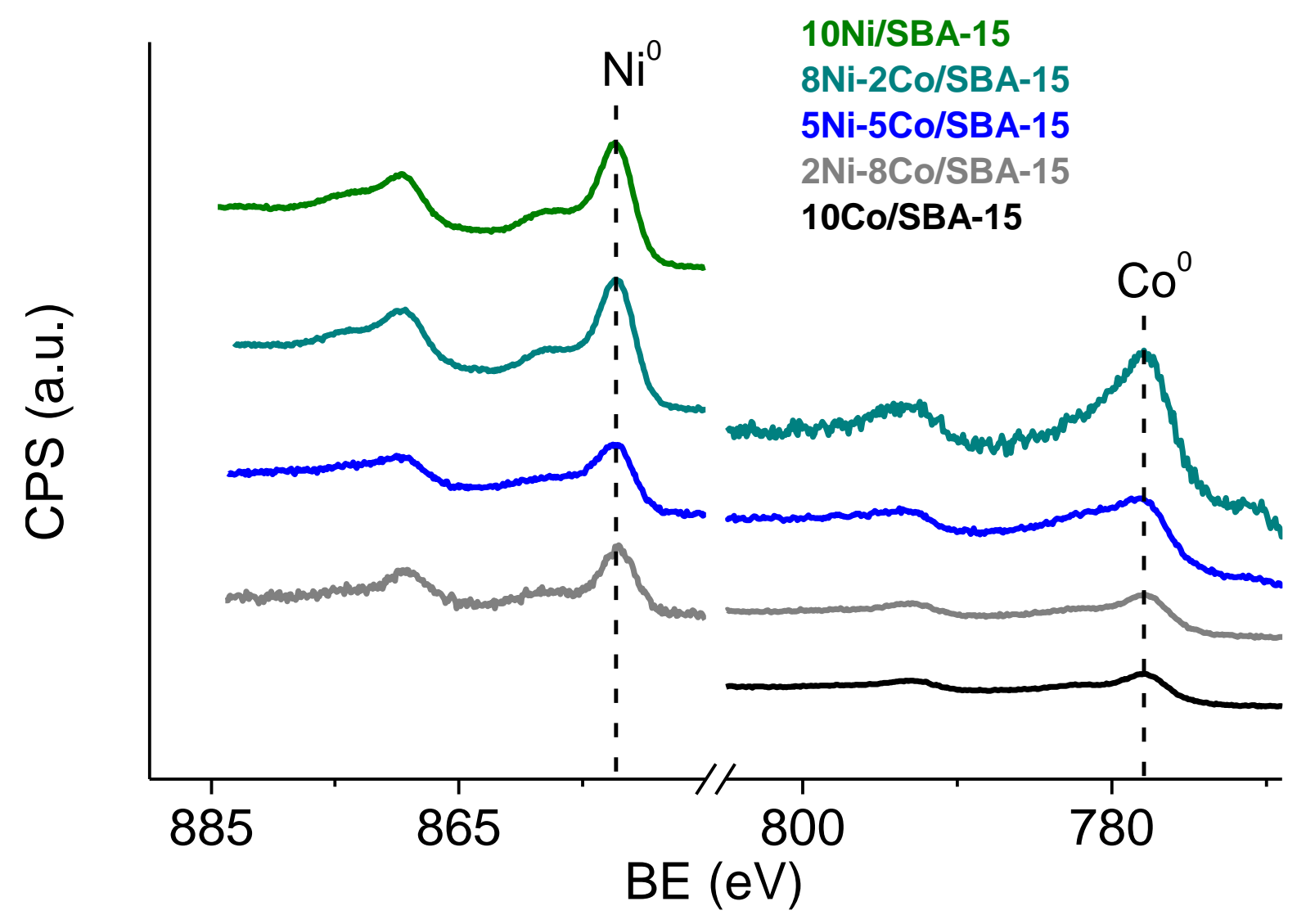

Figure 7. XPS spectra of reduced Ni-Co/SBA-15 systems normalized to metal percentage. 


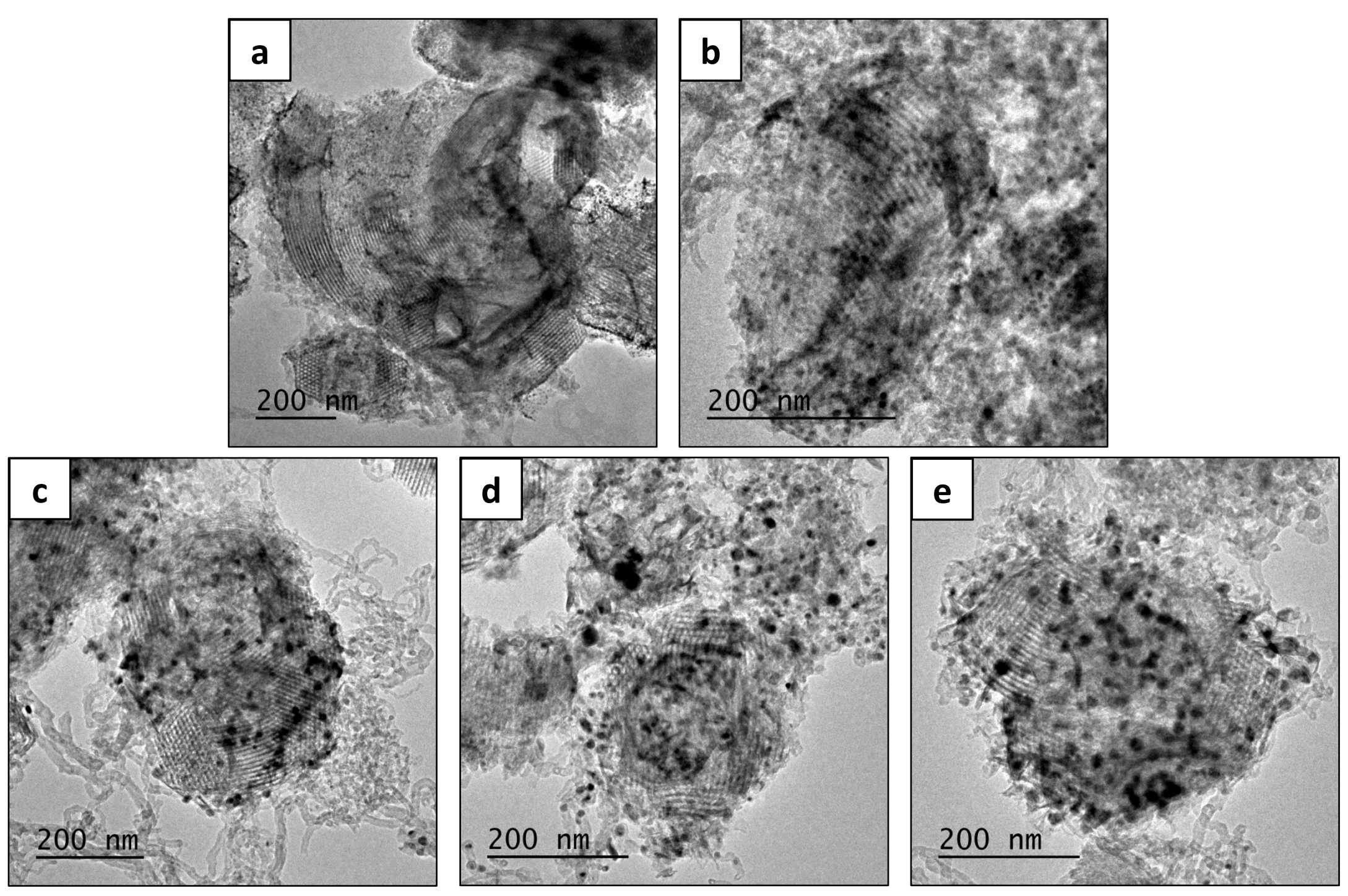

Figure 8. TEM images for 10Ni/SBA-15 (a), 8Ni-2Co/SBA-15 (b), 5Ni-5Co/SBA-15 (c), $2 \mathrm{Ni}-$ $8 \mathrm{Co} / \mathrm{SBA}-15$ (d), and 10Co/SBA-15 (e), after SRE reaction. 


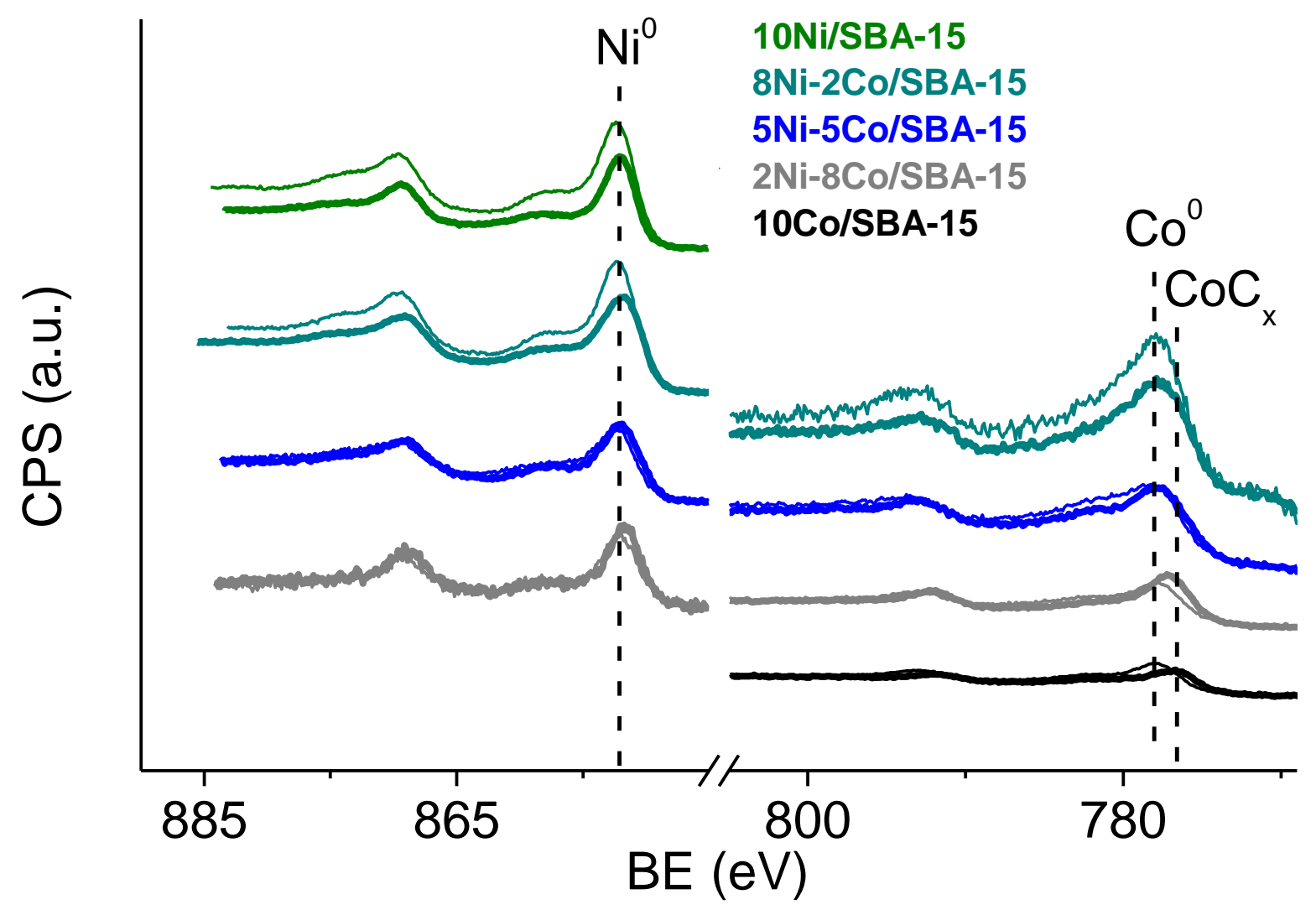

Figure 9. XPS spectra of reduced (thin line) and spent (thick line) $\mathrm{Ni}-\mathrm{Co} / \mathrm{SBA}-15$ systems normalized to metal percentage. 


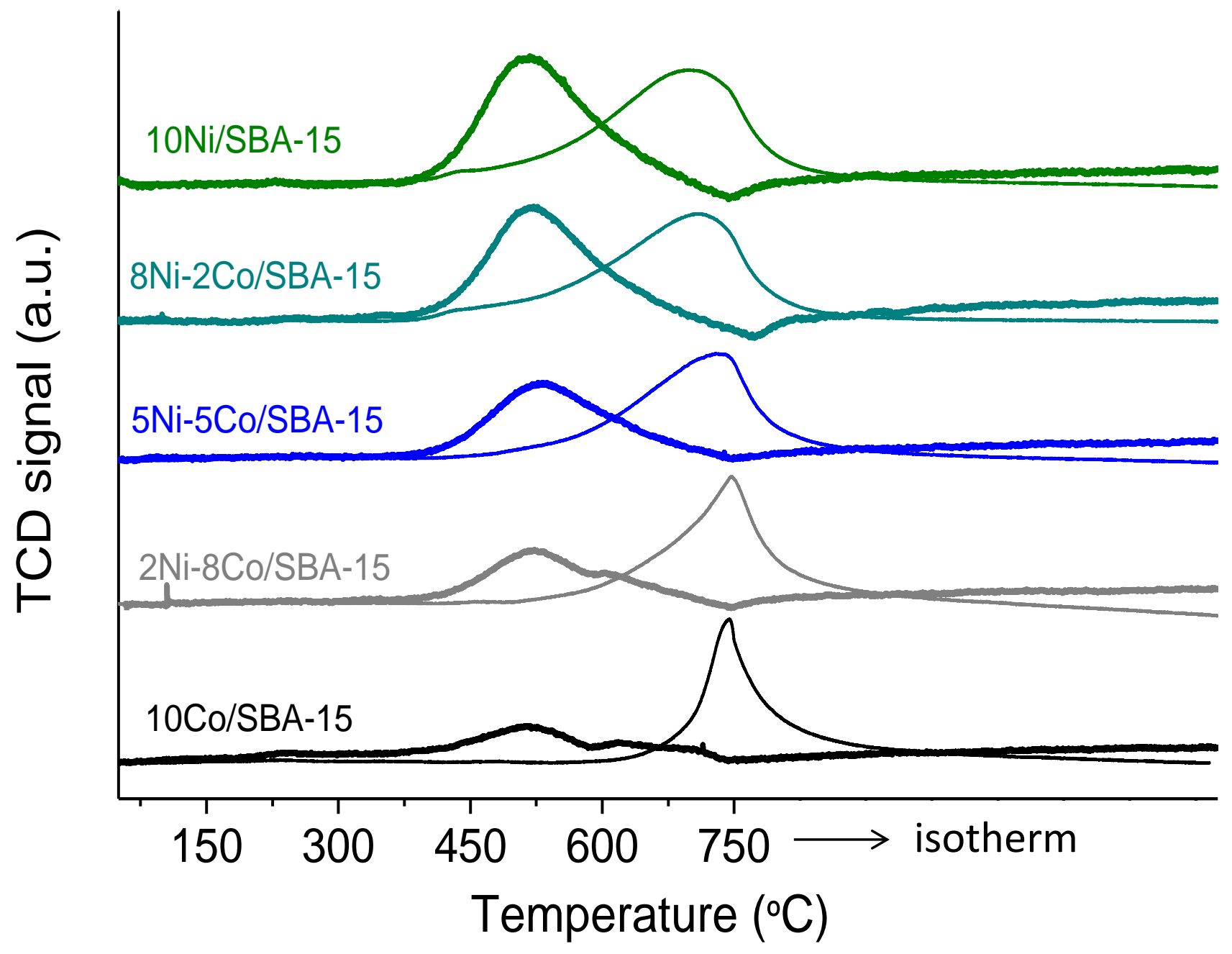

Figure 10. TPR profiles of Ni-Co/SBA-15 catalysts up to $750{ }^{\circ} \mathrm{C}$ plus $1 \mathrm{~h}$ isotherm. Thin line: first TPR. Thick line: second TPR after SRE reaction. 

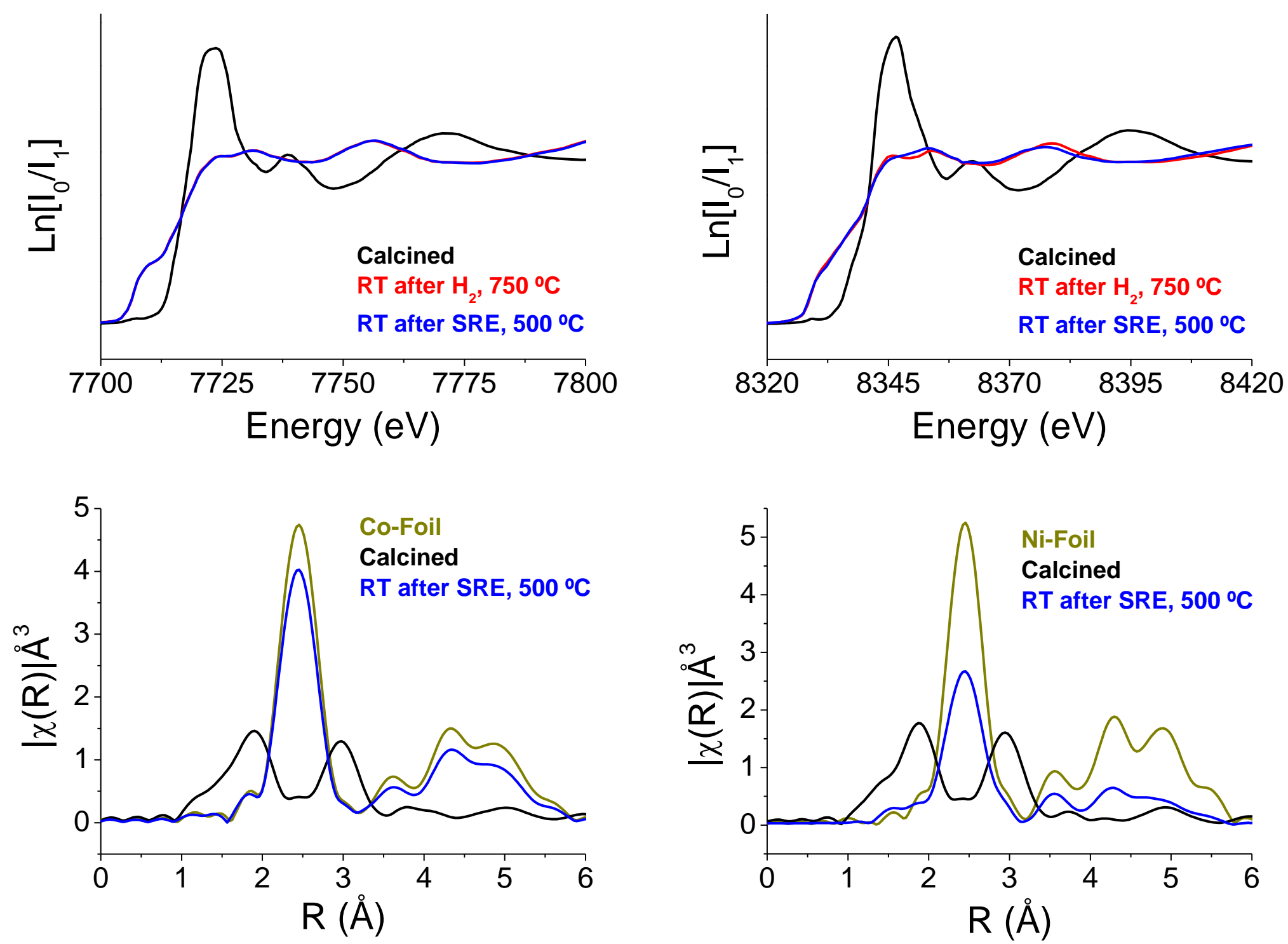

Figure 11. Co (left) and Ni (right) K-edge XANES spectra and Fourier transform functions of the EXAFS oscillations after different treatments. 

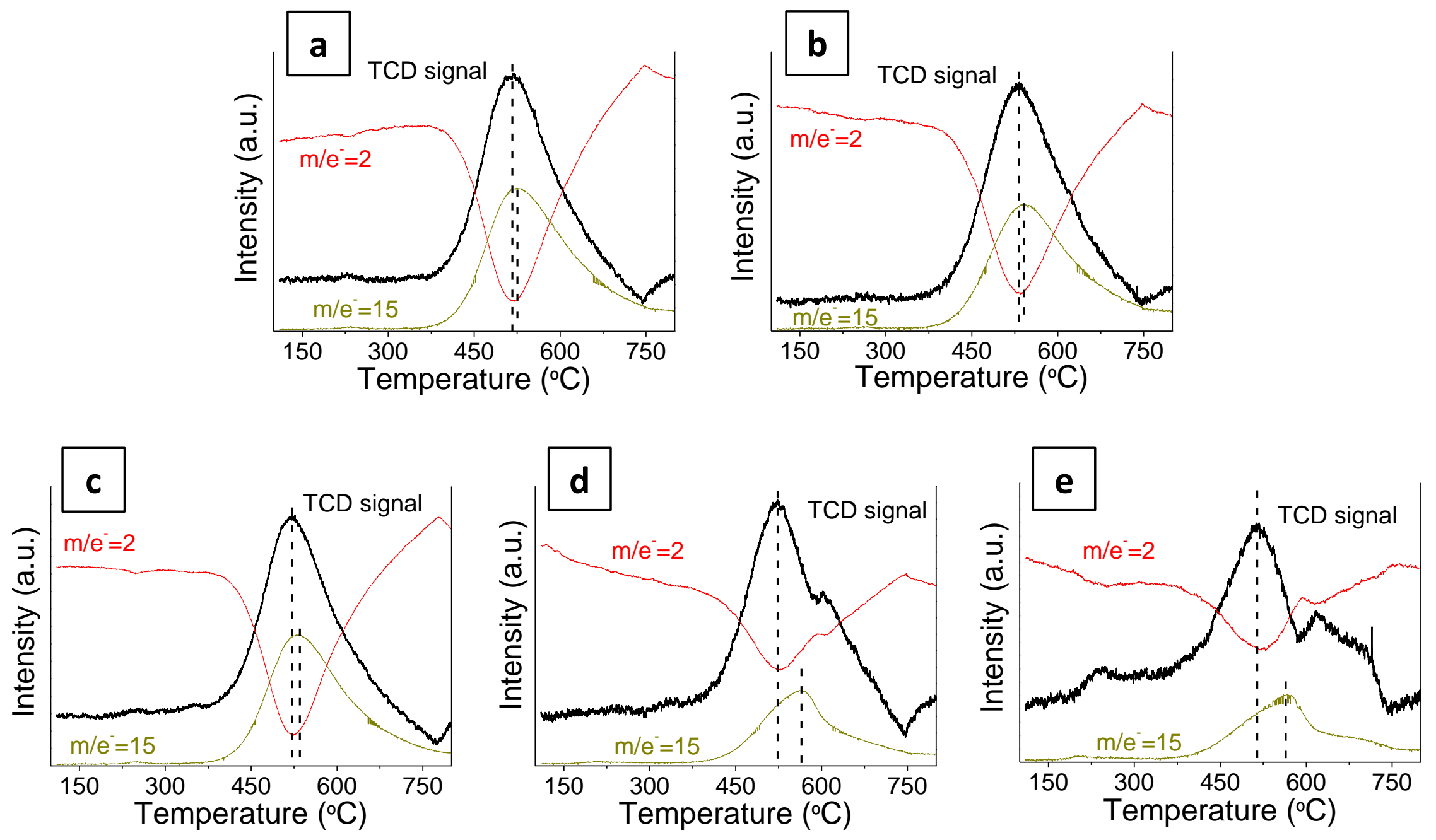

Figure 12. TCD and Mass Spectrometer signals coming from $\mathrm{H}_{2}\left(\mathrm{~m} / \mathrm{e}^{-}=2\right)$ and methane $\left(m / e^{-}=15\right)$ for $10 \mathrm{Ni} / \mathrm{SBA}-15(\mathrm{a}), 8 \mathrm{Ni}-2 \mathrm{Co} / \mathrm{SBA}-15(\mathrm{~b}), 5 \mathrm{Ni}-$ 5Co/SBA-15 (c), 2Ni-8Co/SBA-15 (d), and 10Co/SBA-15 (e). 


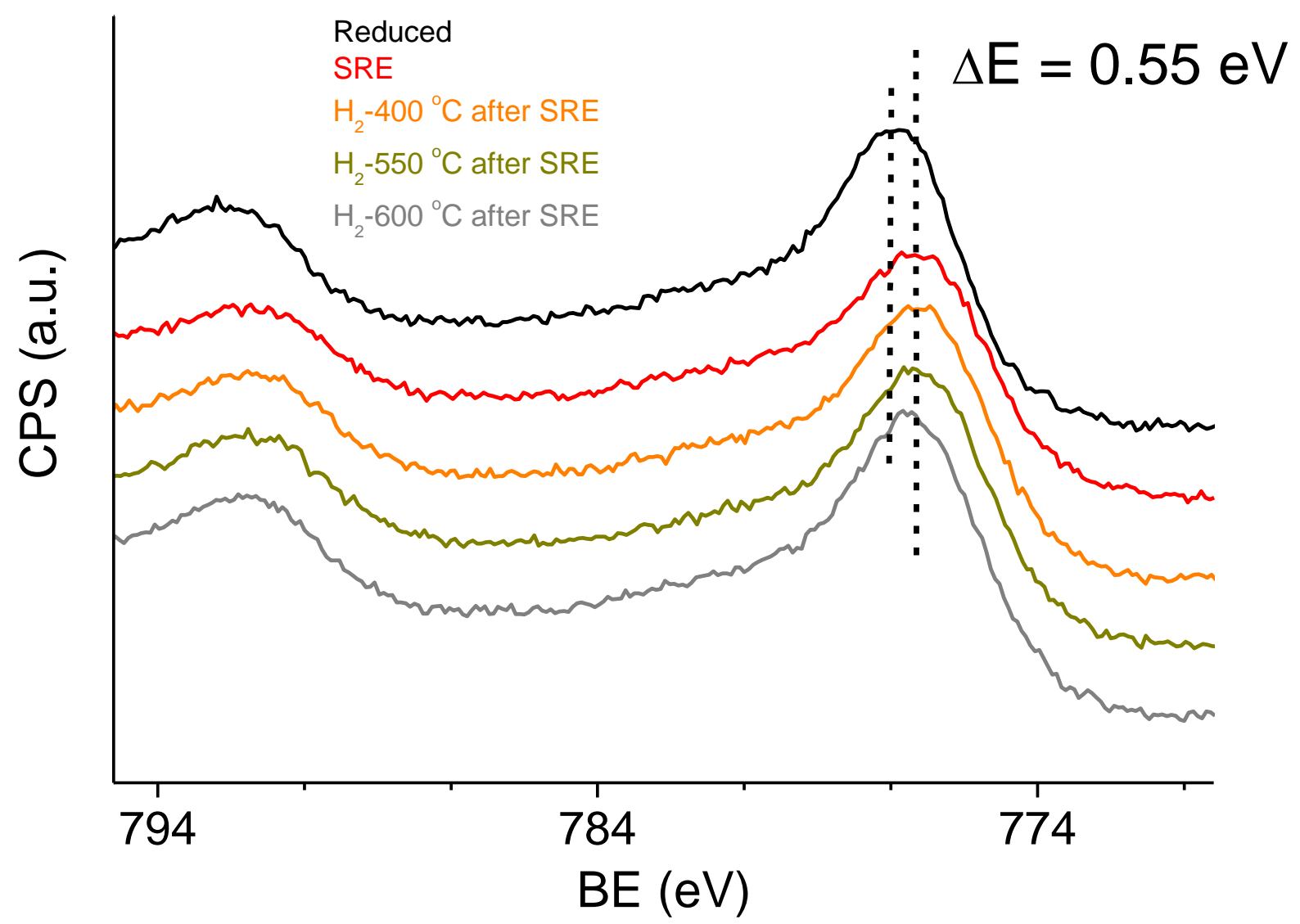

Figure 13. XPS spectra of reduced, spent and hydrogenated 10Co/SBA-15 system. 